Portland State University

PDXScholar

Summer 9-5-2014

\title{
Last Mile Asset Monitoring: Low Cost Rapid Deployment Asset Monitoring
}

Zdenek Zumr

Portland State University

Follow this and additional works at: https://pdxscholar.library.pdx.edu/open_access_etds

Part of the Power and Energy Commons

Let us know how access to this document benefits you.

\section{Recommended Citation}

Zumr, Zdenek, "Last Mile Asset Monitoring: Low Cost Rapid Deployment Asset Monitoring" (2014). Dissertations and Theses. Paper 1967.

https://doi.org/10.15760/etd.1966

This Thesis is brought to you for free and open access. It has been accepted for inclusion in Dissertations and Theses by an authorized administrator of PDXScholar. Please contact us if we can make this document more accessible: pdxscholar@pdx.edu. 


\section{Last Mile Asset Monitoring; \\ Low Cost Rapid Deployment Asset Monitoring}

by

Zdenek Zumr

A thesis submitted in partial fulfilment of the requirements for the degree of

Master of Science

in

Electrical and Computer Engineering

Thesis Committee:

Robert Bass, Chair

James E. Morris

Richard L. Campbell

Portland State University

2014 
(C) Zdenek Zumr 2014 


\section{$\underline{\text { Abstract }}$}

Installation and utilization of residential distribution transformers has not changed substantially over a long period of time. Utilities typically size their transformers based on a formula that takes into account broadly what types and how many dwellings will be connected.

Most new residential dwellings feature 200 Amp service per household with an anticipated energy demand of under $20,000 \mathrm{kWh}$ per year. Average electrical energy consumption varies from state to state but averages to $11,280 \mathrm{kWh}$ per year. Energy demand is expected to fall into a typical residential load curve that shows increased demand early in the morning, then decreasing during the day and another peak early to late evening. Distribution transformers are sized at the limit of the combined evening peak with the assumption that the transformer has enough thermal mass to absorb short overloads that may occur when concurrent loading situations among multiple dwellings arise. The assumption that concurrent loading is of short duration and the transformer can cool off during the night time has been validated over the years and has become standard practice. This has worked well when dwelling loads follow an averaging scheme and low level of coincidence.

With the arrival of electric vehicles (EV's) this assumption has to be reevaluated. The acquisition of an electric vehicle in a household can drive up energy demand by over $4000 \mathrm{kWh}$ per year. Potentially problematic is the increased capacity of battery packs and the resulting proliferation of Level 2 chargers. The additional load of a single Level 2 charger concurring with the combined evening peak load will push even conservatively 
sized distribution transformers over their nameplate rating for a substantial amount of time. Additionally, unlike common household appliances of similar power requirements such as ovens or water heaters, a Level 2 battery charger will run at peak power consumption for several hours, and the current drawn by the EVs has very high levels of harmonic distortion. The excessive loading and harmonic profile can potentially result in damaging heat build-up resulting in asset degradation.

In this thesis I present a device and method that monitors pole mounted distribution transformers for overheating, collect and wirelessly upload data and initiate commands to chargers to change output levels from Level 2 to Level 1 or shut down EV charging altogether until the transformer returns into safe operational range. 


\section{Notice of full disclosure:}

Zdenek Zumr is CTO, cofounder and co-owner of SWEETSense Inc., a company that develops and deploys remote monitoring sensors around the globe. 


\section{Table of Contents}

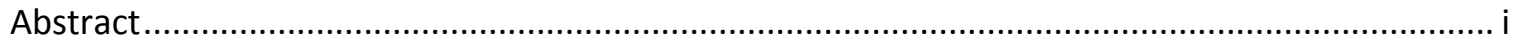

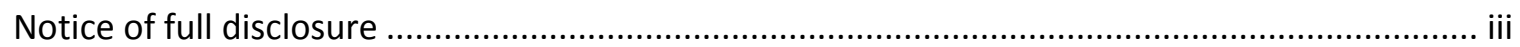

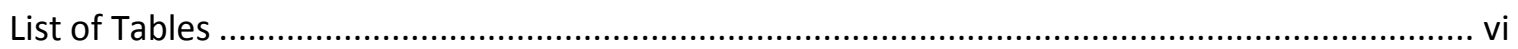

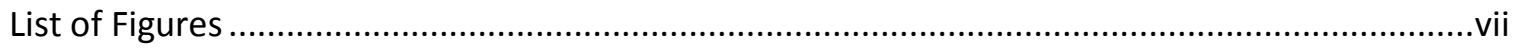

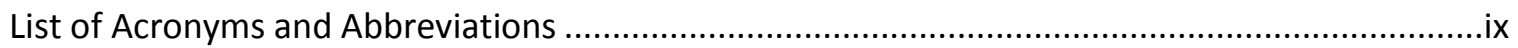

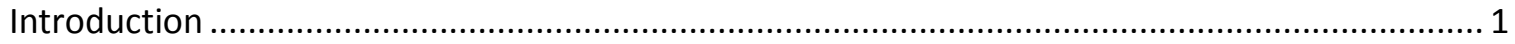

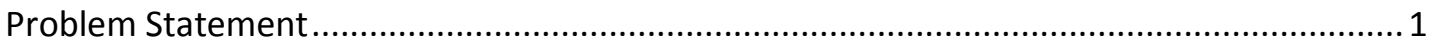

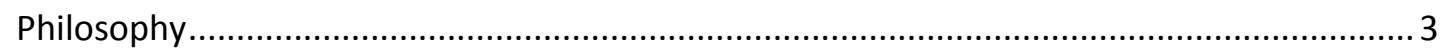

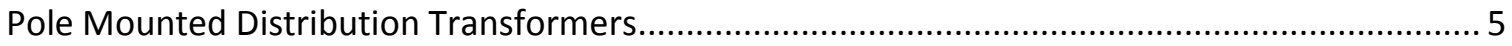

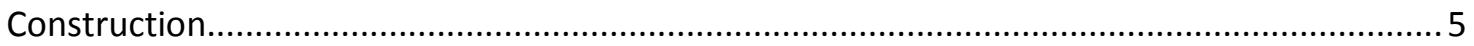

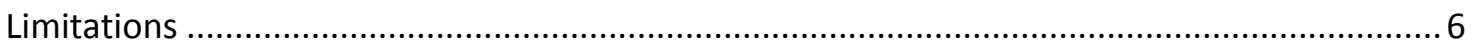

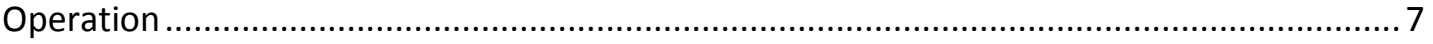

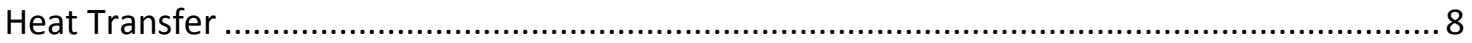

Pole Mounted Distribution Transformer Ratings .......................................................... 11

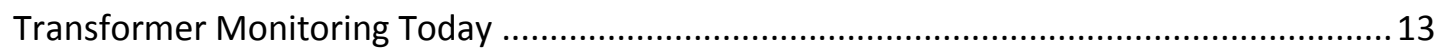

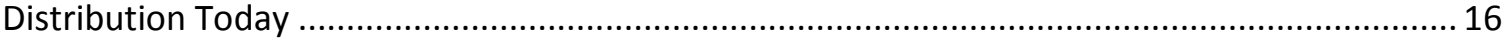

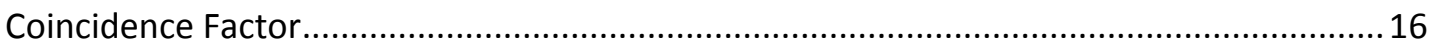

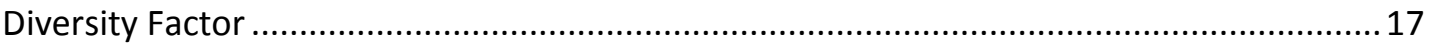

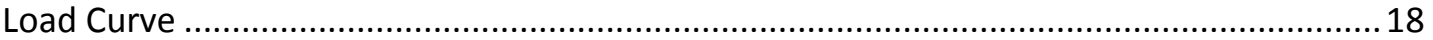

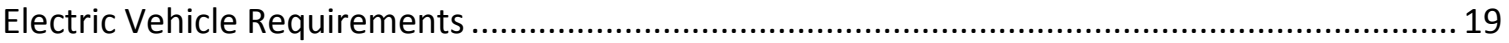

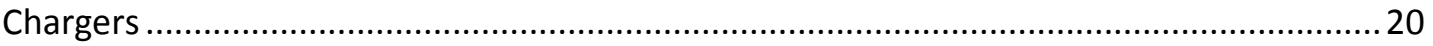

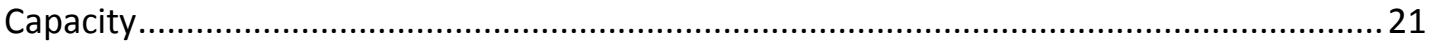

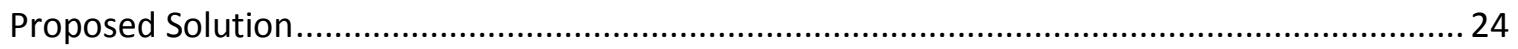

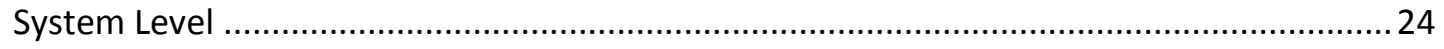

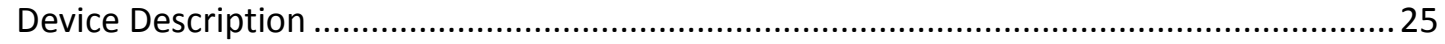

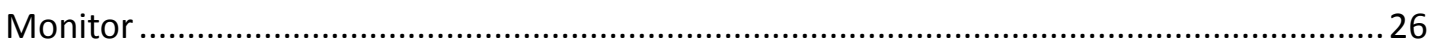

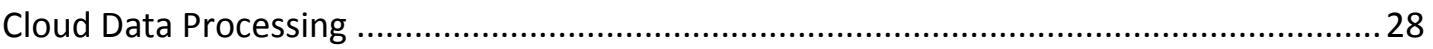

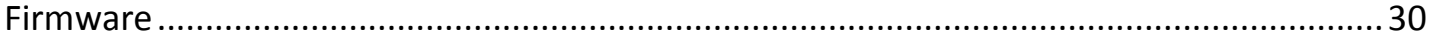

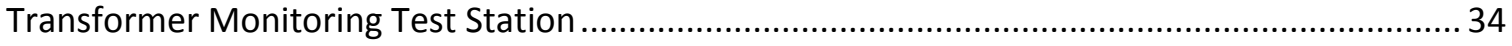

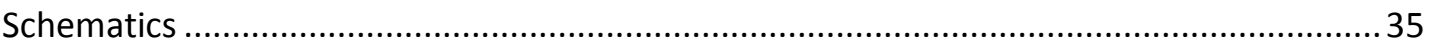

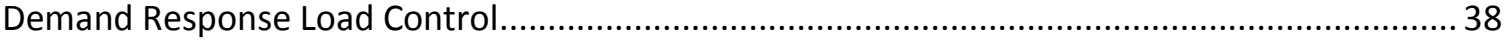

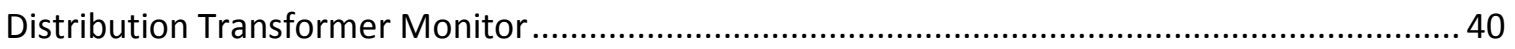

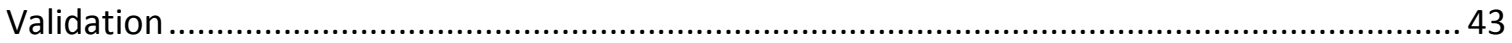


Cost 51

Evolution......

Conclusion

References..... .54

Appendix A Vehicle Data

56

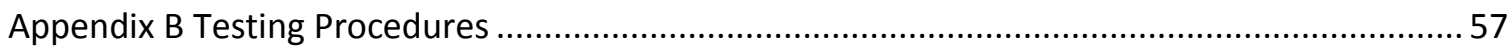

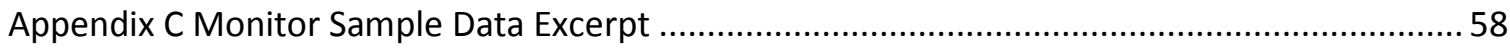




\section{List of Tables}

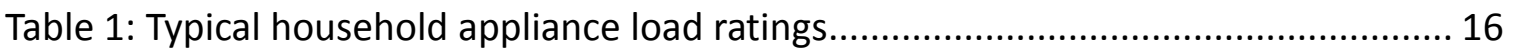

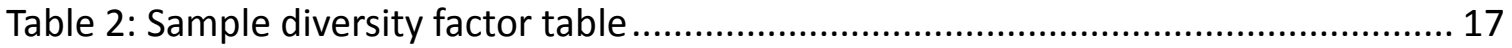

Table 3: Sample calculation Diversity Factor...................................................... 17

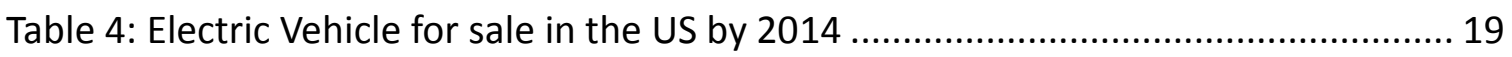




\section{List of Figures}

Fig. 1: Typical pole mounted distribution transformer [3] ...................................... 5

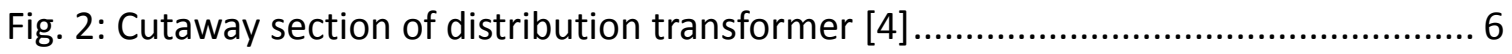

Fig. 3: Hot Spot temperature is depend on Top Oil temperature ................................ 9

Fig. 4: Block diagram for Hot Spot temperature model ............................................. 10

Fig. 5: Transformer temperature profile for IEEE classical thermal model. .................... 12

Fig. 6: Korea Electric Power Data Network's online load monitoring system .................. 15

Fig. 7: Typical load curves for domestic electricity consumption [14] ........................... 18

Fig. 8: Power requirements for electric vehicle chargers [16] ................................... 21

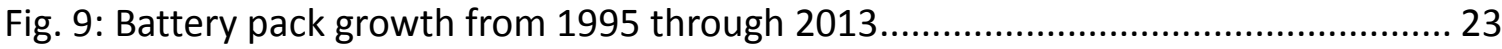

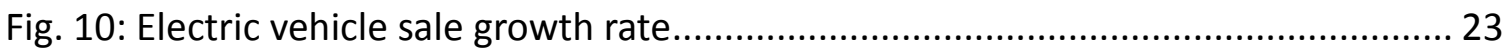

Fig. 11: System level approach to distribution transformer monitoring ......................... 25

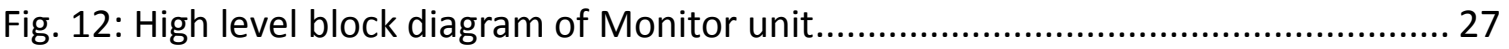

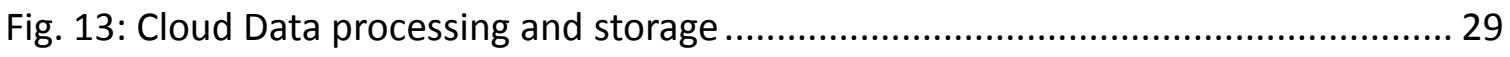

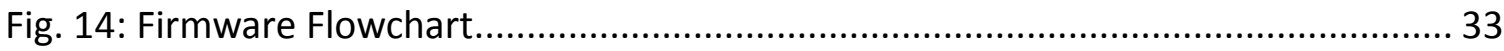

Fig. 15: Primary wiring of Transformer Monitoring Test Station .................................... 34

Fig. 16: Primary wiring of Transformer Monitoring Test Station ..................................... 35

Fig. 17: Secondary wiring of Transformer Monitoring Test Station ............................... 36

Fig. 18: Control schematic of Transformer Monitoring Test Station .............................. 37

Fig. 19: Final Assembly of Transformer Monitoring Test Station .................................... 37

Fig. 20: Schematics and Assembly of Demand Response Load Control .......................... 39

Fig. 21: Distribution Transformer Monitor with modifications...................................... 40 
Fig. 22: Distribution Transformer Monitor mounting

Fig. 23: Daughter board Layout for thermistor bridge .......................................... 43

Fig. 24: Transformer Monitor Heat Shielding.......................................................... 44

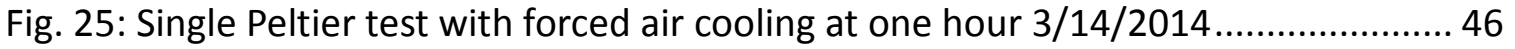

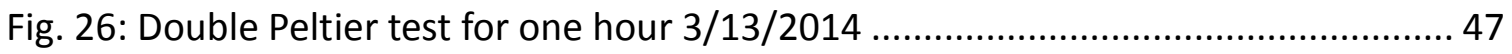

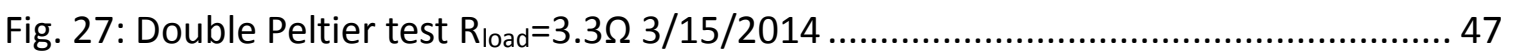

Fig. 28: Uploaded analog data logged from 3/11/2014 to 3/13/2014 .......................... 49

Fig. 29: Board temperature from 3/11/2014 to 3/13/2014 …...................................... 50 


\section{List of Acronyms and Abbreviations}

$\begin{array}{ll}\text { AD } & \text { Analog to Digital converter } \\ \text { AMI } & \text { Advanced Metering Infrastructure } \\ \text { CLK } & \text { Clock source } \\ \text { Com } & \text { Communications port } \\ \text { DTM } & \text { Distribution Transformer Monitor } \\ \text { DMM } & \text { Digital Multi Meter } \\ \text { EPL } & \text { Electronics Prototyping Lab at Portland State University } \\ \text { EV } & \text { Electric Vehicle } \\ \text { FERC } & \text { Federal Energy Regulation Commission } \\ \text { GPRS } & \text { General Packet Radio Service } \\ \text { GPS } & \text { Global Positioning System } \\ \text { IP67 } & \text { Intrusion Protection } \\ \text { IR } & \text { Infra-Red } \\ \text { JTAG } & \text { Joint Test Action Group test access port } \\ \text { MAC } & \text { Media Access Control Address } \\ \text { MSOP } & \text { Mini Small Outline Package } \\ \text { NC } & \text { Numerical Control } \\ \text { NERC } & \text { North American Electric Reliability Corporation } \\ \text { NGO } & \text { Non-Governmental Organization } \\ \text { NiMH } & \text { Nickel Metal Hydride } \\ \text { PCB } & \text { Printed Circuit Board } \\ \text { PIR } & \text { Passive Infra-Red sensor } \\ \text { PMDT } & \text { Pole Mounted Distribution Transformer } \\ \text { ROI } & \text { Return On Investment } \\ \text { RSSI } & \text { Received Signal Strength Indicator } \\ \text { SAE } & \text { Society of Automotive Engineers } \\ \text { SC70 } & \text { SOT-323 package, } 2 \text { x 1.25 mm body } \\ \text { SCADA } & \text { System Control And Data Acquisition } \\ \text { SD } & \text { Secure Digital } \\ \text { SIM } & \text { Subscriber Identification Module } \\ \text { SMD } & \text { Surface Mount Device } \\ \text { SOIC } & \text { Small Outline Integrated Circuit, 3.9 mm wide body } \\ \text { SOT-23 } & \text { Small Outline Transistor package, } 2.9 \times 1.3 \text { mm body } \\ \text { SQL } & \text { Structured Query Language } \\ \text { SWEETLab } & \text { Sustainable Water Energy Environmental Technology Laboratory } \\ \text { UART } & \text { Universal Asynchronous Receiver/Transmitter } \\ \text { URL } & \text { Universal Resource Locator } \\ & \end{array}$




\section{Introduction}

\section{Problem Statement}

Although efforts are underway in new developments to install distribution feeders underground and distribution transformers in underground vaults or on surface concrete pads, pole mounted distribution transformers (PMDTs) are ubiquitous in utility districts. The basic design of PMDTs has not changed over the years and expertise gained by generations of utility engineers drives installation and sizing of residential distribution transformers. Typically PMDTs are sized to run at 50\% average nameplate load based on a formula that takes into account broadly what types and how many dwellings will be connected.

In the past, residential service consisted of a 60 Amp panel with around a dozen branch circuit. These days most new residential dwellings feature 200 Amp service, but can be as high as 400 Amps in upper income homes in new developments. Residential service presumes an anticipated energy demand of under 20,000 kWh per year. Average electrical energy consumption varies from state to state but averages to $11,280 \mathrm{kWh}$ per year [1]. Energy demand is expected to fall into a typical residential load curve that shows increased demand early in the morning, then decreasing during the day and another peak early to late evening. This curve retains its characteristic even with electrical heating or air conditioning in place. In the past distribution transformers were sized conservatively with ample head room. That has paid off as energy demand per household has increased over the years. Because of increased energy demand these days transformers are often near their nameplate rating when during the evening peak short time coincident loads can 
push beyond the nameplate rating. It is acceptable to operate under the assumption that transformers have enough thermal mass to absorb these short overloads because the transformer can cool off during the night time. This operational model has been validated over the years and has become standard practice. This has worked well when dwelling loads follow a coincidence factor scheme and coincidence between households is low. With the arrival of electric vehicles (EVs) this assumption has to be reevaluated. EV sales are growing exponentially and battery pack capacities are growing with increased vehicle size. The acquisition of an electric vehicle in a household can drive up energy demand by over $4000 \mathrm{kWh}$ per year [2]. The steady increase of battery pack capacity results in the proliferation of Level 2 chargers. The additional load of a single Level 2 charger concurring with the combined evening peak load will push even conservatively sized distribution transformers beyond their nameplate rating. Unlike common household appliances of similar power requirements such as ovens or water heaters a Level 2 battery charger will run at peak power consumption of $6-10 \mathrm{~kW}$ for several hours, and the current drawn by the EVs has very high levels of harmonic distortion. The excessive loading and harmonic profile can potentially result in damaging heat build-up in the transformer.

Utilities are in various stages of implementing smart grid technologies. Some have installed "smart meters" with the ability for bidirectional communication to gather detailed energy use data in short time increments. The advanced metering infrastructure (AMI) infrastructure could be harnessed to provide distribution transformer load data and to interrupt EV charging should load exceed a predetermined value over time. However, to take advantage of AMI, utilities have to develop and implement data handling and 
processing algorithms as well as data storage and reference facilities. Further, customer data has to be correlated to specific assets such as feeders, fuses, breakers and distribution transformers. Few utilities are in a position to take advantage of the installed AMI hardware at this time. If the growth trend in EV distribution continues there may soon be a gap in last mile asset monitoring and protection that will require discrete solutions until large scale supervisory control and data acquisition (SCADA) catches up.

In this thesis we present a conceptual device and method that can monitor pole mounted distribution transformers for overheating, collect and wirelessly upload data, and initiate commands to chargers to change output levels or shut down EV charging all together until the transformer returns into safe operational range. Data acquisition is independent of existing SCADA systems utilizing cloud storage and processing and thus is freely scalable. Integration of data for operational and maintenance purpose is possible through privileged access to data bases.

\section{Philosophy}

Asset monitoring in power systems is typically accomplished by the same SCADA systems that operate the power system. These SCADA systems are an integral part of power generation and distribution systems and have to be designed and operated with the same operational requirements as the system itself with respect to reliability and uptime. NERD and FERC regulations set tight rules for equipment that is involved in the operation of the power grid with respect to interoperability, date security and safety. These requirements drive expense up, require dedicated communication lines, physical 
security and require careful planning and execution of system layout and changes. When additional monitoring requirements arise; be it because of temporary outages, natural disasters, accidents, etc., monitoring systems can be deployed but require assembly from discrete off the shelf components that have to be tied into existing infrastructure to meet power and communication requirements.

Such a monitoring system may consist of a selection of sensors to measure electrical parameters such as temperature, vibration, oil turbidity or binary switch states that connect to a data logger. A wired or wireless communications unit with requisite antenna passes on the gathered information. Power supplies, batteries and/or solar chargers complete the system. Suitable enclosures are required to hold and protect the components. Selection of components, interconnections and set up require engineering time and each application is custom built. Deployment may still pose challenges in sub-stations where clearances may be tight and running wires may pose unacceptable risks. 


\section{Pole Mounted Distribution Transformers}

\section{Construction}

An oil-filled steel can with welded seams holds a single phase transformer, Fig 1. The lid seals the can with a rubber gasket to provide protection from contamination and holds the bushing for the primary. Primary input is typically in the $12.47 \mathrm{kV}$ range, line to ground, with a secondary low voltage, split phase for dual $180^{\circ}$ opposed $120 \mathrm{~V}$ line to ground or single $240 \mathrm{~V}$ line to line output. The transformer takes up only the lower $1 / 2$ to $1 / 3$ of the can and is submerged in oil to provide passive convective cooling.

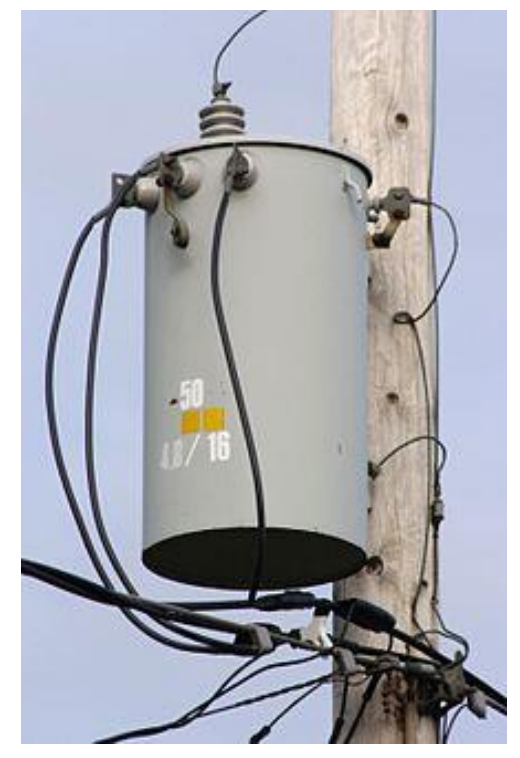

Fig. 1: Typical pole mounted distribution transformer [3]

Oil heated by $I^{2} R$, hysteresis and eddy current losses is less dense, thus rises up from the core to the top where it is displaced to the outside wall that in turn is cooled by convective air cooling. The cooled oil sinks to the bottom and enters the core where it is heated again. To increase cooling capacity the surface area of the transformer may be 
equipped with flat cooling fins or tubular loops. This simple construction, without moving parts, guarantees a high degree of reliability.

Because of the relatively large can volume to core ratio, distribution transformers can absorb substantial overloads and the resulting heating for short amounts of time.

\section{Limitations}

The kVA rating of a distribution transformer is limited by the materials used in construction, physical build and acceptable temperature rise. Aluminum or copper wire is wrapped in paper for insulation and spun around a central core made from thin sheets of laminated silicon steel, Fig. 2. Electrical resistive losses will heat the wires and insulation that has to be kept below damaging temperature.

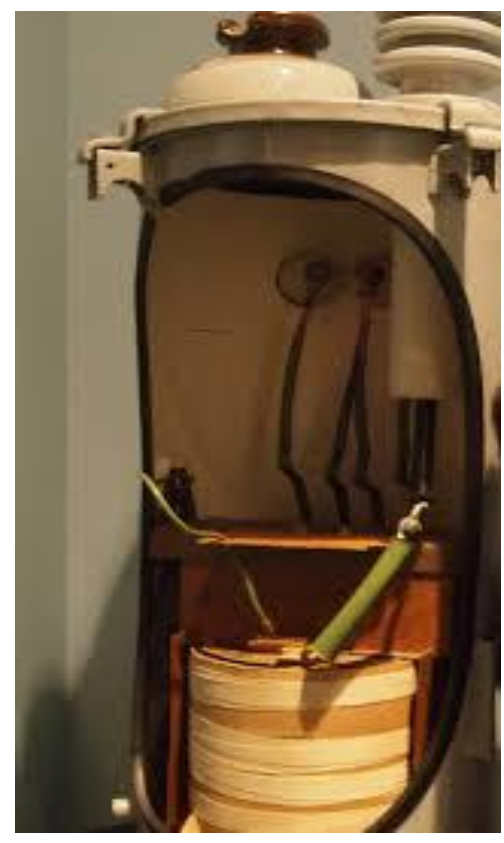

Fig. 2: Cutaway section of distribution transformer [4] 
The alternating current imparts mechanical stresses that vibrate the leads and coil by magnetic forces at $60 \mathrm{~Hz}$. Convection cooling is uneven and results in hot spots and additional mechanical stresses. Magnetic losses and eddy currents in the silicon steel will heat up the core. The paper insulation deteriorates over time and temperature by depolymerization and abrasion from mechanical stresses. The cooling oil contains dissolved gases that come out of solution as temperature increases, forming bubbles that reduce effective cooling and create hot spots. As oil heats up it expands pressurizing the can. If expansion is excessive an overpressure valve will release hot gases. As the transformer cools down air will be admitted into the transformer containing moisture and oxygen which deteriorates the oil and forms sludge that settles at the bottom of the can.

\section{Operation}

Despite the above detriments due to the simple construction and generous sizing in past installations, pole mounted transformers (PMDTs) have long lifespans of 25 to 40 years or more. These transformers have been able to keep up with growing electrical demands of modern households and will do so far into the future. Since PMDTs are used across the United States and interface between utilities and customers electric service in all areas, rural, commercial and domestic, and because of the large numbers of these transformers in operation this thesis bases its findings on data across the US for pole mounted transformers. While there may be regional differences in load distribution, seasonal variations and electrical codes, the impact the electric vehicle distribution will have on distribution transformer loading will be universal. 


\section{Heat Transfer}

Transformer heating is the primary cause of loss of life. Temperature within the transformer is the result of a dynamic process of heat generation, heat transfer and cooling. Differential equations that describe heat transfer for distribution and power transformers have been established and accurately define the dynamic behavior as presented in: "Thermal Model for Power Transformers Dynamic Loading." [5] The oil temperature at the top of the fluid column has been found to adequately account for the thermal effects that contribute to loss of life. The top oil temperature model is governed by the following equation:

$$
\frac{I_{p u}^{2} \beta+1}{\beta+1} \cdot\left[\Delta \theta_{O-R}\right]^{1 / n}=\tau_{O} \frac{d \theta_{O}}{d t}+\left[\theta_{O}-\theta_{A}\right]^{1 / n}
$$

Where:

$I_{p u}=$ Load current per unit, $\beta=$ Ratio of load to no-load losses, $\Delta \theta_{0-R}=$ Rated top oil rise over ambient $[\mathrm{K}], \tau o=$ Top oil time constant $[\mathrm{min}], \theta_{o}=$ Top oil temperature $\left[{ }^{\circ} \mathrm{C}\right], \theta_{A}=$ Ambient temperature $\left[{ }^{\circ} \mathrm{C}\right], n=$ Exponent which defines non-linearity.

The equation describes the heat generated by resistive heating of the oil is balanced by the convective cooling lest the oil heats up increasing the temperature gradient and thus increasing convection.

For a transformer to fail it needs to fail in only one location. That location is a hypothetical "hot spot" where deterioration is most advanced and thus limits the life of the transformer. The physical location of this hot spot within the transformer is not 
relevant and may vary depending on design and variations in the manufacturing process.

The hot spot temperature calculation is:

$$
\frac{I_{p u}^{2}\left[K_{\theta}+\frac{P_{E C-R}}{K_{\theta}}\right]}{1+P_{E C-R}} \cdot\left[\Delta \theta_{H-R}\right]^{1 / m}=\tau_{H} \frac{d \theta_{H}}{d t}+\left[\theta_{H}-\theta_{o}\right]^{1 / m}
$$

Where:

$\theta_{H}=$ Hot spot temperature, $\left[{ }^{\circ} \mathrm{C}\right], P_{E C-R}=$ pu unit eddy losses at rated load and hot spot location, $K_{\theta}=$ Resistance correction due to temperature change, $\Delta \theta_{H-R}=$ Rated hot spot rise over oil $[\mathrm{K}], \tau \mathrm{\tau}=$ Hot spot time constant $[\mathrm{min}], m=$ Exponent which defines non-linearity.

The equation says that the hot spot temperature is driven by resistive heating as well as core losses that are balanced by convective cooling. However hot spot temperature is dependent on cooling oil temperature by the temperature dependent factor $K \theta$.

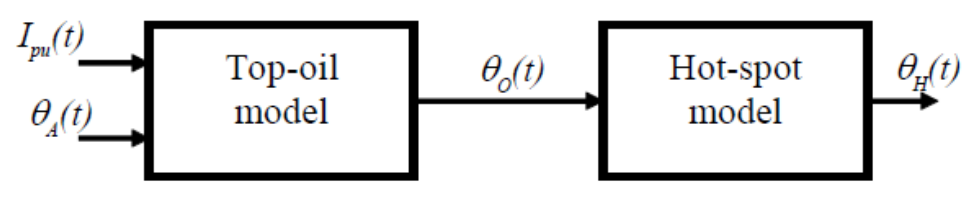

Fig. 3: Hot Spot temperature is depend on Top Oil temperature

Top oil temperature and hot spot temperature depend on transformer specific time constants $\tau_{\mathrm{O}}$ and $\tau_{\mathrm{H}}$ that impart a time delay between increased heating and an eventual increased in cooling due to increased temperature gradients. This behavior is advantageous since short term overloading of the transformer will only impart heat on the cooling oil gradually, Fig. 3, preventing venting to the atmosphere. However the time 
delay also limits our ability to capture overheating conditions that arise due to large load shifts by way of measuring top oil temperature, such as turning on a large appliance or turning on a Level 2 charger. PMDTs are engineered with resilience to overloads in the design.

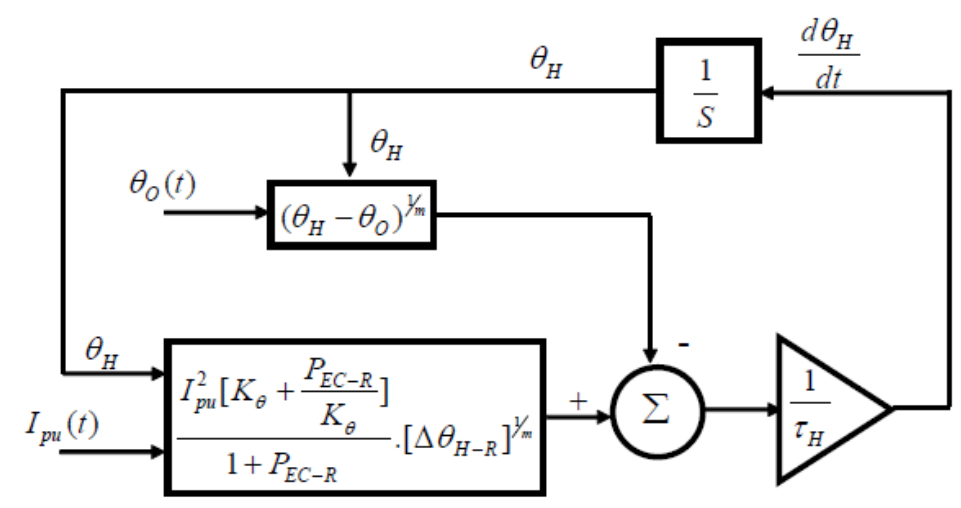

Fig. 4: Block diagram for Hot Spot temperature model

In the thermal loading theory it is important to remember that temperatures continue to rise even after a load has been removed, Fig. 4. Thus, ideally load switching would be proactive. Failing that, rate of temperature rise in the transformer may be a better trigger to turn off excessive loads rather than waiting for the transformer temperature to rise. This would ensure that the distribution transformer temperature remains at levels where abnormal loss of asset life would not be experienced adhering to the current distribution loading philosophy of today. 


\section{Pole Mounted Distribution Transformer Ratings}

The PMDTs ratings are based on the winding-core system size and the thermal medium type such as air, mineral oil, synthetic or others. The transformer nameplate output capability in kVA is a function of the highest temperature in which the transformer windings-insulation system can be operated without abnormal loss of life. The loss of life has been based on the degradation of the cellulose insulation paper in which the windings are wrapped. Furthermore, the hottest spot temperature is a major factor in establishing transformer ratings. The IEEE guide for Loading Mineral-Oil-Immersed Transformers, IEEE C57-1995, states: "The hottest-spot temperature at rated load is the sum of the average winding temperature and a hottest spot allowance, usually 15 degrees Celsius." Moreover, determined from tests, the "Normal Life Expectancy" for mineral oil type distribution transformer occurs with the hot spot temperature operated at $110{ }^{\circ} \mathrm{C}$ continuously for about 20.55 years (180,000 hours). [6] This is based on the insulation paper chemical reaction to heating in the typical mineral oil emerged environment and subsequent depolymerization, or break down of fibers. [7]

Knowing the hottest-spot temperature requirements, the transformer rating is based on the transformer physical design including the mass of the conductive winding material, the iron core, the fittings and the volume of oil as well as other material properties. Then the physical design and location of the windings is optimally selected such that the hot-spot temperature remains as low as possible while in operation. This location considers optimal heat dissipation at some internal point in the windings near the core and in some region where flux line density is at a maximum for heat sourcing. Additional constraints considered while determining the optimal configuration is the optimal efficiency at the 
expected load factor. Distribution transformer peak efficiency occurs at about $60-70 \%$ load of nameplate rating. [8] The limits of efficiency are the core losses. With these considerations, the transformer is given a nameplate rating that will meet the aforementioned heating criteria, the desired efficiency and short circuit duty. This means that the distribution transformer is designed with a standard temperature rise over ambient, at $30{ }^{\circ} \mathrm{C}$. Older transformers are rated for a $55^{\circ} \mathrm{C}$ rise for an average winding temperature of $85^{\circ} \mathrm{C}$ and a $65{ }^{\circ} \mathrm{C}$ hot spot rise over ambient. Modern transformers with improved insulation paper allow for $65^{\circ} \mathrm{C}$ rise for $95{ }^{\circ} \mathrm{C}$ average winding temperature and $80{ }^{\circ} \mathrm{C}$ hot spot temperature rise not to exceed $110{ }^{\circ} \mathrm{C}$. [9]

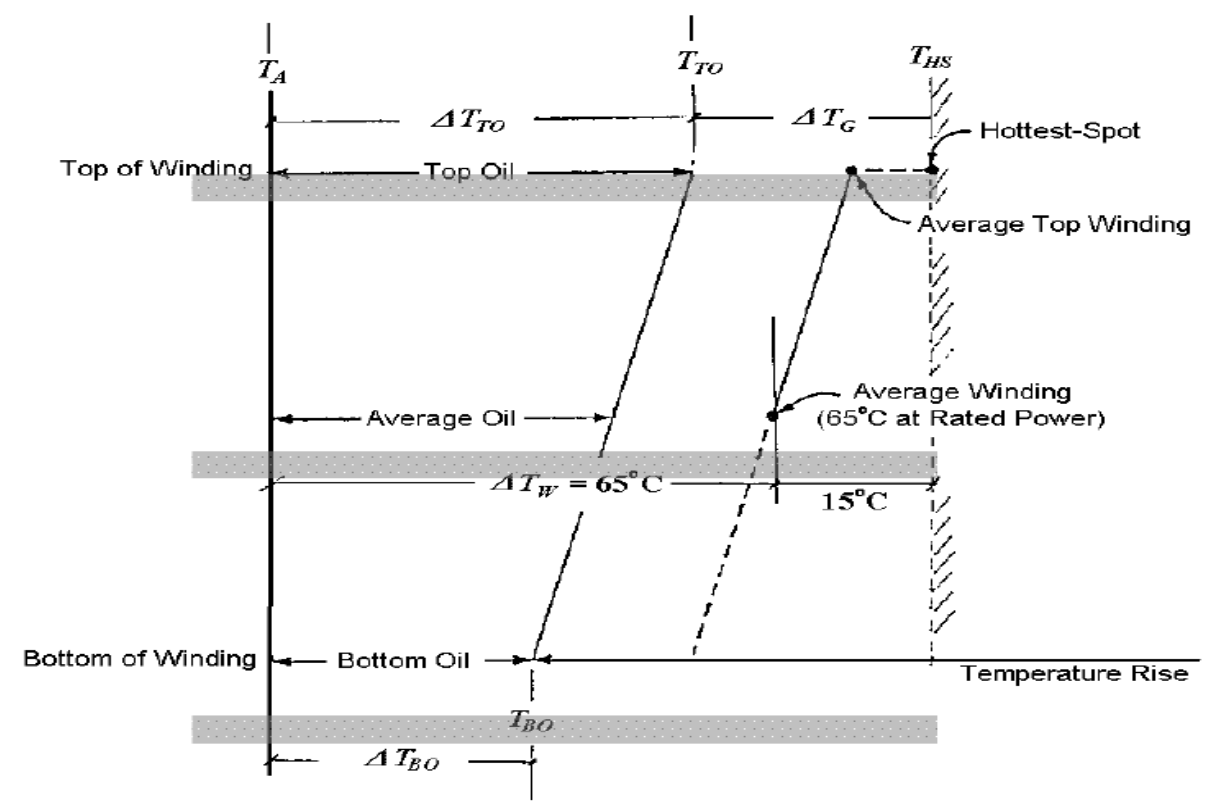

Fig. 5: Transformer temperature profile for IEEE classical thermal model. [10]

These are the Power Industry theoretical characteristics for distribution transformers, Fig. 5. If transformers are operated within these tolerances, no excessive loss of life will be expected. The loss of life for a transformer is based on the insulation paper degradation 
as measured by either tensile strength or degree of polymerization. However in practical use distribution transformers may be allowed to reach higher temperatures.

The general aging acceleration factor is as follows:

$$
\text { Per Unit Life }=A^{*} \exp ^{\left[\frac{B}{\theta_{H}+273}\right]}
$$

Where $\theta_{H}$ is the winding hottest spot temperature in ${ }^{\circ} \mathrm{C}, \mathrm{A}$ and $\mathrm{B}$ are transformer specific constants. [11]

The typical-normal expected life of a distribution transformer is anywhere between 25 to 40 years depending on the loading, environmental factors, manufacturing flaws and through faults experienced by the unit.

\section{Transformer Monitoring Today}

Modern transformer monitoring is divided into two aspects; operational monitoring and transformer life monitoring. Transmission transformers represent a substantial asset to utilities due to the financial expense and limited availability. Thus transmission transformers are protected with breakers and load monitoring equipment to prevent catastrophic events. These systems are tied in with SCADA systems at substations that inform operators in real-time on the state of the transformer. Transformer life monitoring utilizes a variety of sensors that provide feedback maintenance and life extension of associated hardware. Sensors include temperature probes, cooling oil quality assessment, arcing detectors and vibration monitoring. Data can be logged locally or uploaded and 
archived remotely where it can be reviewed to establish appropriate maintenance

protocols.

However pole mounted distribution transformers are not equipped with this kind of

equipment since the cost of monitoring would exceed the cost of the transformer.

However:

“... over the past five years, Korea Electric Power Data Network's online load monitoring system for a distribution transformer has been widely used in Korea. Using this system as a condition monitoring system for a distribution transformer, users can reduce management costs and prevent damage to the distribution transformer caused by overloads and imbalance of loads. But, this system still cannot check some important information such as insulating oil temperature and heat aging status. So, the company has been developing a new online condition monitoring system in distribution transformers over the past year. It is a new type of distribution transformer with four types of built-in sensors, including CT (current transformer), PT (potential transformer), oil temperature sensor and heat aging sensor. It measures various parameters on the internal status of transformers. The signals measured in built-in sensors are interfaced with the external data processing unit and are transmitted to the upper layer system. The details of sensing data include load current, voltage, load factor, oil temperature, and heat aging of insulating oil. When a fault sign such as overcurrent, overvoltage, overload, outage, and overheating of insulating oil occurs on a distribution transformer, the alarm function will be activated and the HMI displays this information on the screen immediately. Also, the SMS (Short Message Service) server automatically transmits a fault message to the line crew who attend to the faulty transformer. This provides users with rapid recovery from faulty operation of the distribution transformer.” Fig. 6 [22] 


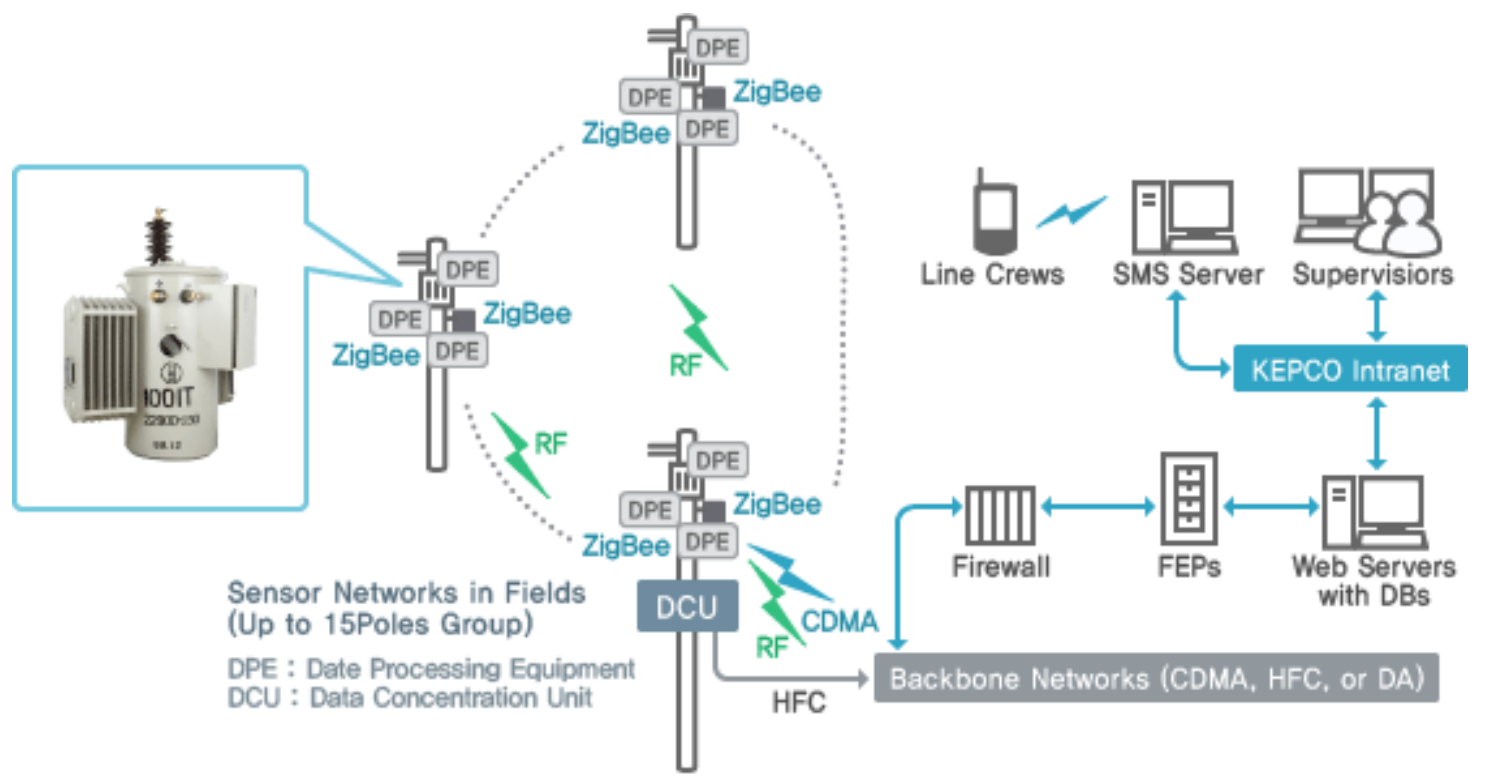

Fig. 6: Korea Electric Power Data Network's online load monitoring system Further research reveals that wired distribution transformer control and monitoring equipment has been proposed in the past and patents applied for including frequency overlay communication dating back as far as the 1920's. But these proposed technologies have not found widespread utilization. 


\section{Distribution Today}

The distribution system today has been planned and designed for conventional residential households, small commercial and small retail settings. Assumptions are that there will be a typical amount of major electrical appliances, electrical equipment and lighting proportional to the square footage of the facility served. The assumption for the distribution transformers is that facilities have differing occupation rates and that electrical equipment attached in any facility will not be operated at the same time. This behavior is referred to as diversity factor and coincidence factor. Both are based on experience and past observation that may be specific to utilities and regions.

\section{Coincidence Factor}

The coincidence factor is based on the ratio of diversified load to maximum possible system load. An example of the demand and demand factor for residential type customers is listed in Table 1:

\begin{tabular}{|c|c|}
\hline Typical residential Appliances & Typical Power Rating (Watts) \\
\hline Water Heater & 4500 \\
\hline Range / Oven & 8000 \\
\hline Central Air Conditioner & 6000 \\
\hline Clothes Dryer & 5000 \\
\hline Dishwasher & 2000 \\
\hline Lighting, Fans, Appliances, Other & 7500 \\
\hline Sum of Total Connected Electrical Equipment & 33000 \\
\hline
\end{tabular}

Table 1: Typical household appliance load ratings

The sizing for distribution transformers is typically based on practical observed loading pattern. If the combined peak load draw is $20 \mathrm{~kW}$, then the coincident demand factor is: 
$20 / 33=0.60606$ or $60.6 \%$. It is likely that the total apparent power of connected electrical equipment exceeds the nameplate rating of the distribution transformer. [12]

\section{Diversity Factor}

The diversity factor applies the concept that not all dwellings connected use power at the same time amongst different dwellings. The more customers there are connected to a distribution transformer, the lower the diversity factor, as the Table 2 illustrates:

\begin{tabular}{|c|c|c|c|c|c|c|c|c|c|c|}
\hline Number of Customers & 1 & 2 & 3 & 4 & 5 & 6 & 7 & 8 & 9 & 10 \\
\hline Diversity Factor & $100 \%$ & $90 \%$ & $75 \%$ & $65 \%$ & $63 \%$ & $62 \%$ & $61 \%$ & $61 \%$ & $61 \%$ & $61 \%$ \\
\hline Number of Customers & 11 & 12 & 13 & 14 & 15 & 16 & 17 & 18 & 19 & 20 \\
\hline Diversity Factor & $60 \%$ & $59 \%$ & $58 \%$ & $58 \%$ & $57 \%$ & $57 \%$ & $56 \%$ & $54 \%$ & $54 \%$ & $54 \%$ \\
\hline
\end{tabular}

Table 2: Sample diversity factor table

As an example, assume the estimated peak electrical power usage for a 1200 square foot home is $13 \mathrm{~kW}$ in the summer and $15 \mathrm{~kW}$ in the winter. The acceptable overload factor for this utility is $140 \%$ for the summer peak and $160 \%$ for the winter peak. A sample calculation is presented in Table 3; assuming 4 x 1200 square foot homes are connected to a distribution transformer:

\begin{tabular}{|c|c|c|}
\hline & Summer Peak & Winter Peak \\
\hline KW for 1200 Square Foot home & 13 & 15 \\
\hline KW for 4 X 1200 sq. ft. homes & 52 & 30 \\
\hline Appling the 4 home diversification factor i.e. x.65 & 33.8 & 40 \\
\hline select a 25 kVA transformer with x 1.4 and 1.6 overload factor & 35 & 39 \\
\hline
\end{tabular}

Table 3: Sample calculation Diversity Factor 
Based on the above calculations, the $25 \mathrm{kVA}$ transformer is acceptable per the design requirements which are $65 \%$ of the seasonal peaks. Utilities may present with different design philosophies than this example. [13]

\section{Load Curve}

The combination of diversity and coincidence results in a typical load curve, Fig. 7. Nighttime loads are low but build in the morning when occupants rise and prepare for that day. Water heaters and electric heat sources kick in for short periods of time. During the day loading is reduced as some homes are unoccupied, peaking again in early evening as inhabitants return from work. The evening peak is drawn out with heating, cooking, lights and electronic equipment drawing loads.

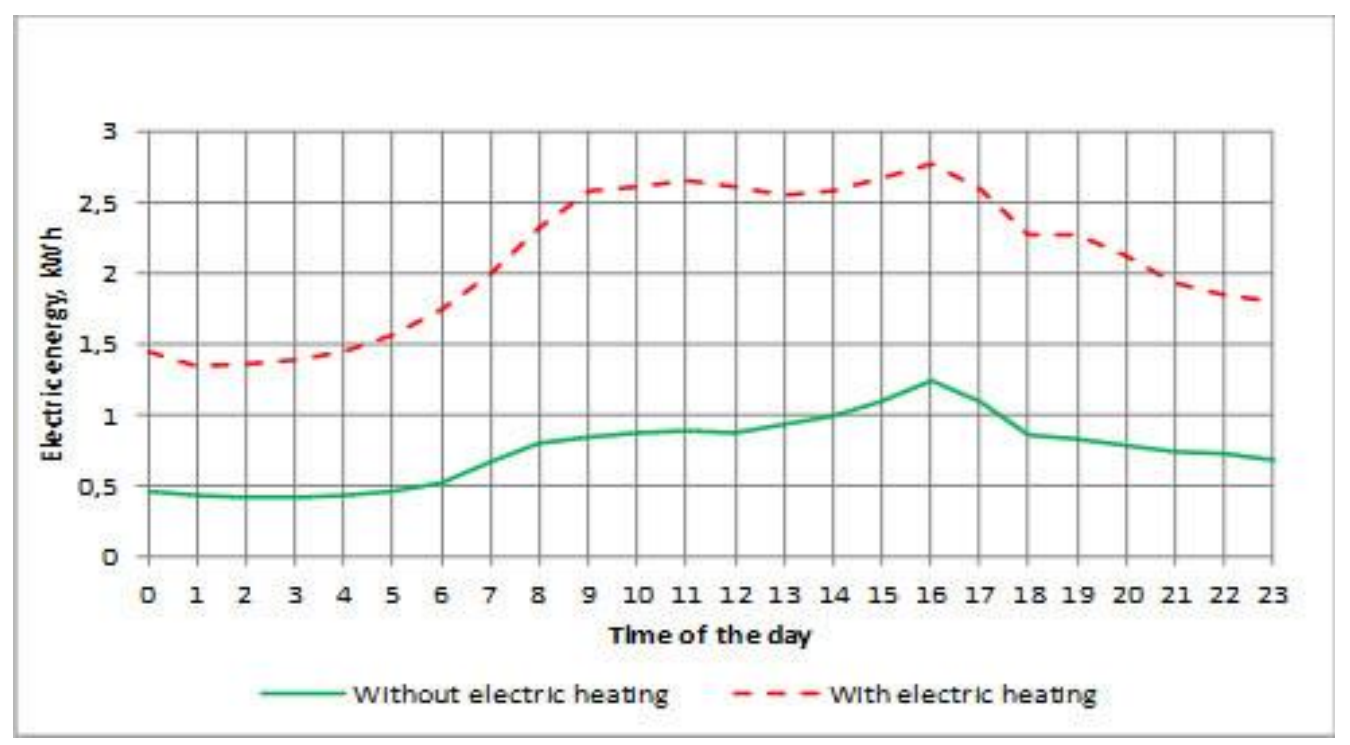

Fig. 7: Typical load curves for domestic electricity consumption [14] 


\section{Electric Vehicle Requirements}

The presence of an electric vehicle (EV) can increase the energy demand of a typical household by $30 \%$ or $4000 \mathrm{kWh}$ per year, under the assumption that EVs are acquired to replace internal combustion engine vehicles. The energy requirements for personal transportation are computed from the 13,500 miles per year average millage driven times an average Watt-millage for a mid-sized car, like a Ford Focus. [15] Most EVs have on board chargers that allow the driver to top-off the battery from 120 VAC, 15 A receptacles. These chargers are referred to as Level 1 chargers. Higher charging rates can be accomplished with Level 2 chargers that provide up to $7.2 \mathrm{~kW}$ charge capacity at $240 \mathrm{~V}$, $30 \mathrm{~A}$. These are stationary chargers hooked up to dedicated branch circuits at home or about town that the vehicle can pull up to. Table 4 shows available electric vehicles in the US at the end of 2013: [15]

\begin{tabular}{|c|c|}
\hline Car & Battery Capacity [kWh] \\
\hline Leaf & 24 \\
\hline Smart EV & 17.6 \\
\hline Volt & 16.5 \\
\hline Tesla 60 kWh & 60 \\
\hline Tesla 85 kWh & 85 \\
\hline Ford Focus & 23 \\
\hline Chevy Spark & 21.3 \\
\hline Prius Plug in & 4.4 \\
\hline Mitsubishi i-MiEV & 16 \\
\hline Honda Fit EV & 20 \\
\hline Toyota Rav4 & 41.8 \\
\hline
\end{tabular}

Table 4: Electric Vehicle for sale in the US by 2014 
Because of the power handling requirements, these chargers tend to be large and heavy and are often left out of vehicles to reduce vehicle weight, reduce cost and increase efficiency by reducing dynamic load on the drive system. Through advances in power electronics and subsequent reduction in size and weight some vehicles, such as the 2014 Toyota RAV4 EV have a Level 2 charger on board.

\section{Chargers}

From Table 4 it is apparent that battery pack capacities vary greatly in size, averaging about $30 \mathrm{kWh}$ at the end of 2013. Level 1 chargers, whether vehicle mounted or stationary plug into standard household receptacles and don't need special accommodation. At $120 \mathrm{~V}$ and 15 A rating outlets can provide $1800 \mathrm{~W}$ of power, but with the unavoidable losses Level 1 chargers deliver about $1500 \mathrm{~W}$ charge to the battery. That means a $30 \mathrm{kWh}$ battery would have to be plugged in for over 20 hours to receive a complete charge. Thus Level 1 chargers can only be considered for topping off partially discharged batteries such as after a morning commute or during a short shopping trip. For most vehicle owners that is sufficient since the majority of vehicle trip are under one hour duration and less than 45 miles distance. Unlike gasoline vehicles EVs don't use energy when stuck in traffic jams.

For faster charging, Level 2 chargers are available and becoming more popular with EV buyers. These chargers, when not already integrated into the vehicle, can be leased with the vehicle or bought outright. They require a dedicated branch circuit, heavy gauge wiring, professional installation and typically a building permit. The power requirements are similar to a clothes dryer or Range/Oven combination, Fig. 8. The maximum output 
of a Level 2 charger is limited by its design but it can be throttled to draw less power if needed.
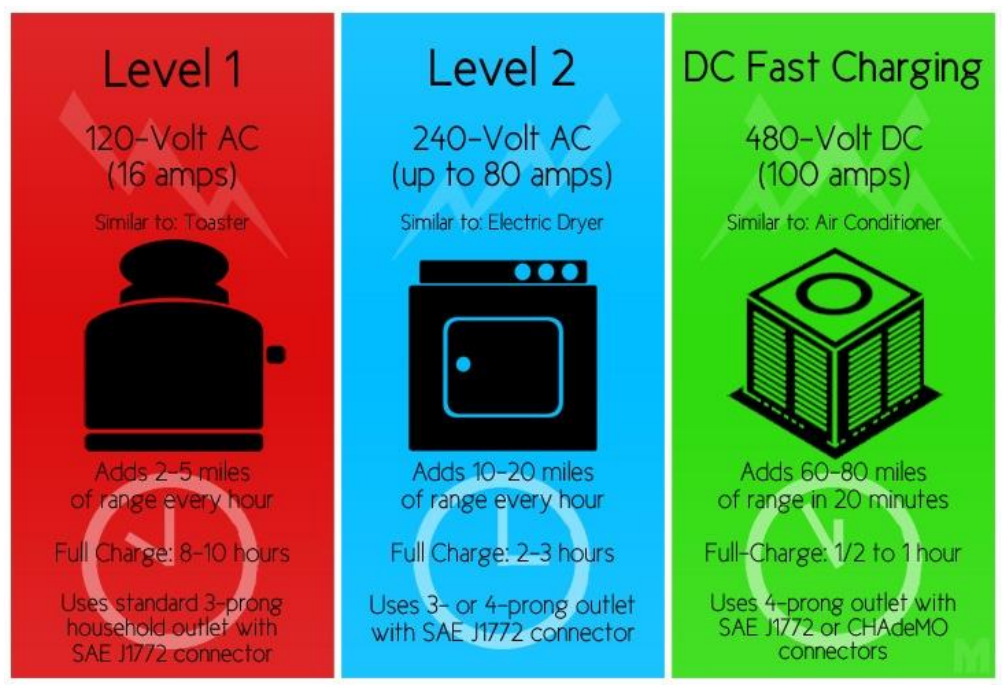

Fig. 8: Power requirements for electric vehicle chargers [16]

The fastest chargers require high voltage, three phase service and are available only in industrial or commercial settings or at dedicated charging facilities.

Alternatively DC fast charging options with up to $600 \mathrm{VDC}$ and 400A are getting codified in SAE J1772 rules. These rules however are incompatible with the most widely utilized $\mathrm{CHaDeMo}$ standard, setting a hurdle for wide spread adoption. Few EVs can make use of the charging capacity these chargers provide at this point.

\section{Capacity}

Over the years battery packs have grown as new battery technologies became available, Fig. 9; volume pricing drives cost down, vehicle sizes increase and power requirements grow. It can be expected that this trend will continue, raising the charger power 
requirements accordingly. As EVs become common, waiting for a charge to complete will not be an option and high power charging facilities will become the norm. The effect is compounded by exponentially growing car sales, Fig. 10, driven by a variety of factors such a tax incentives, low electric energy cost, stable electricity cost, preferential driving privileges in high occupancy lanes, preferential parking and a green image as well as status symbol. The perceived absence of emissions, wear and tear and scheduled maintenance is appealing to the technophobe. For these reasons EV sales will continue to grow even when financial incentives are removed. Where EVs proliferate, particularly urban centers in the coastal areas, utilities need to evaluate their infrastructure and be prepared to meet the added demand electric transportation will place on the grid.

The proliferation of electric vehicles places a particular problem for distribution transformers. Unlike traditional household loads of similar power demand, ranges, water heaters and clothes dryers that require peak power only for relatively short periods of time, coincident for under an hour, EV chargers operate at peak load continuously. To charge a $30 \mathrm{kWh}$ battery pack a Level 2 charger rated at $240 \mathrm{~V} 40 \mathrm{~A}$ will remain in full power mode for almost four hours.

The additional load of almost $10 \mathrm{~kW}$ that a single Level 2 charger consumes concurring with the coincident evening peak load could push even conservatively sized distribution transformers over their nameplate rating. The consequence is that distribution transformers will operate in overload conditions on a regular basis, reducing efficiency, driving up temperature and reducing the life of the transformer. Two Level 2 chargers fed from the same transformer and powered on after an evening commute will skew the 
diversity factor closer to 1 and could lead to equipment failure unless asset monitoring is in place.

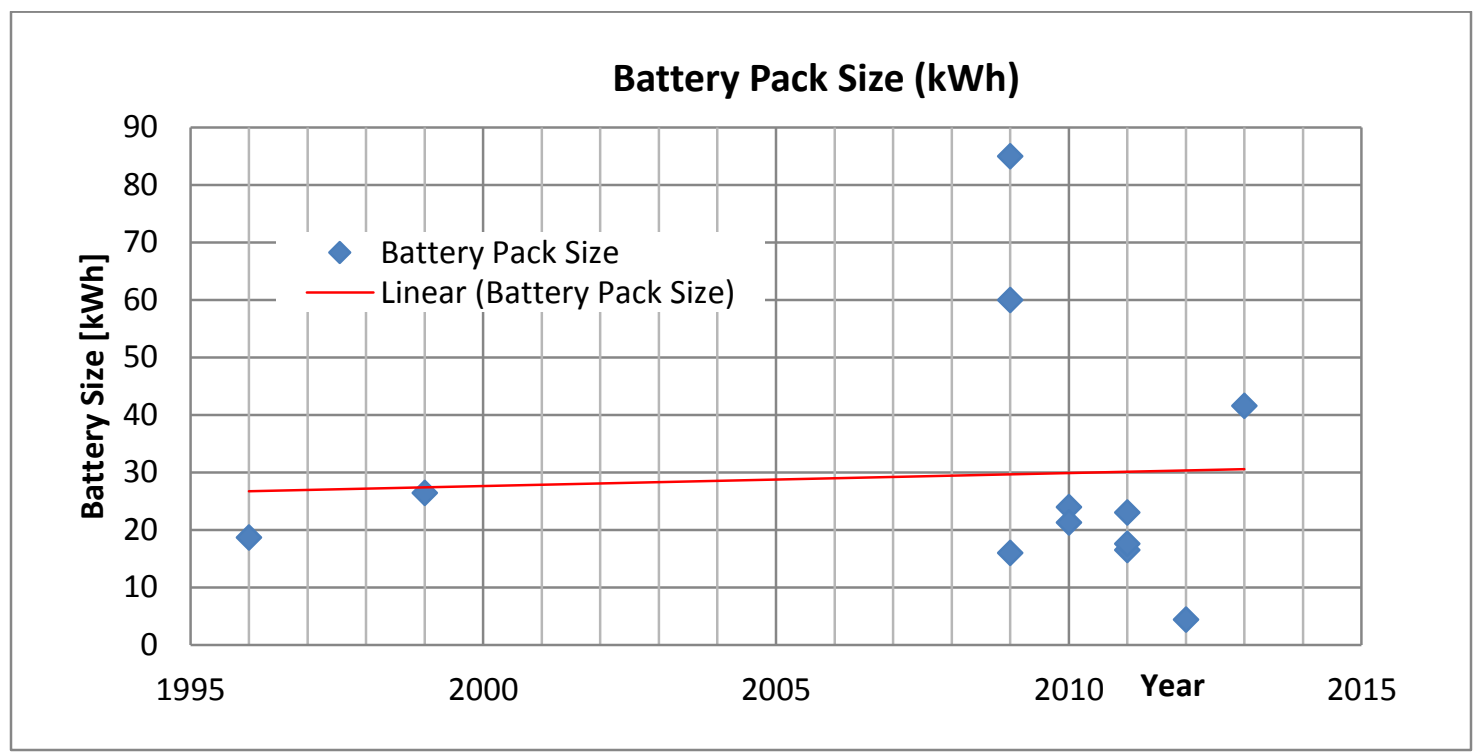

Fig. 9: Battery pack growth from 1995 through 2013

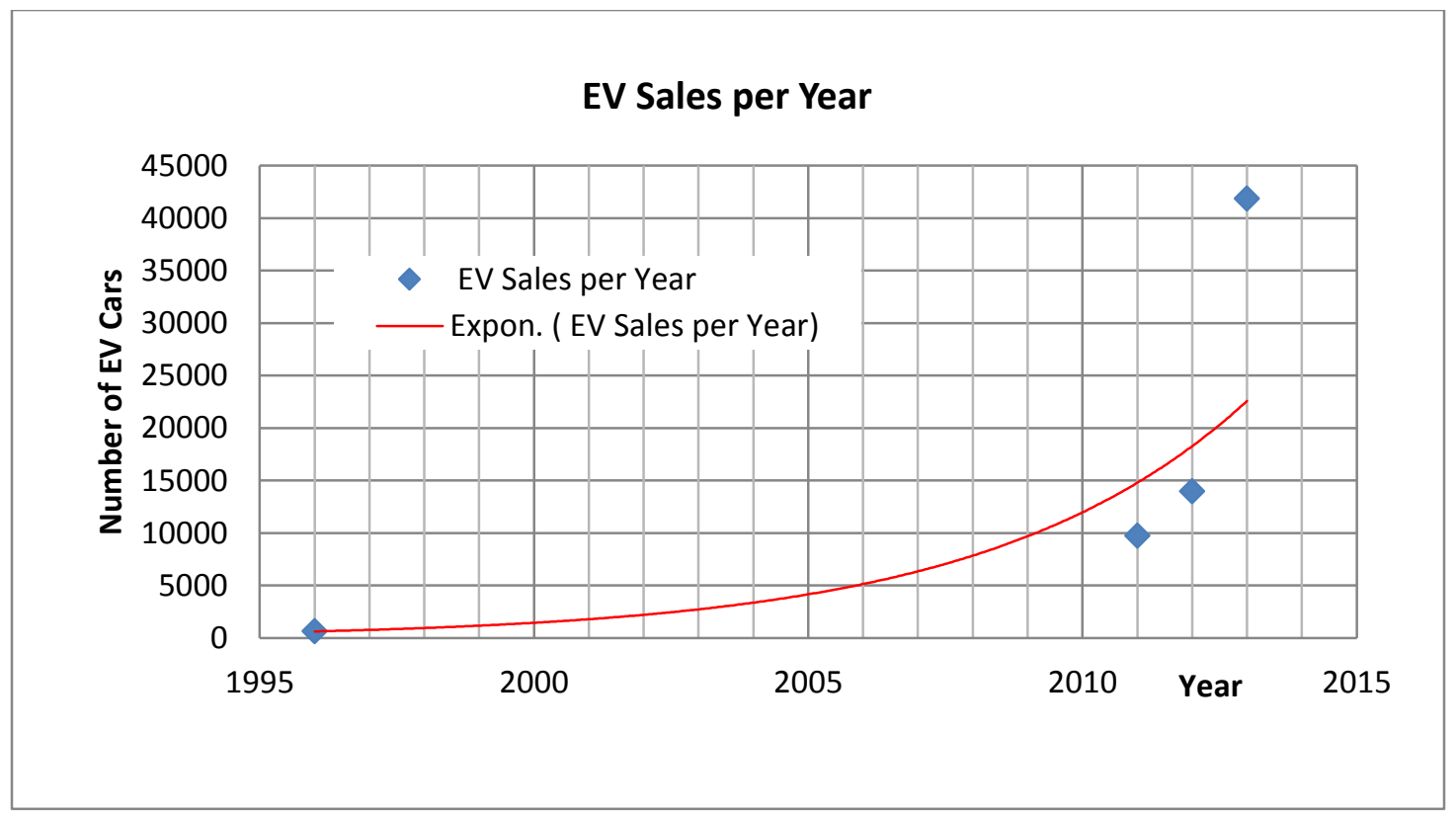

Fig. 10: Electric vehicle sale growth rate 


\section{Proposed Solution}

\section{System Level}

A solution for distribution transformer thermal overload protection integrating AMI technology has been proposed by Saifur Rahman, et. all [17] that would use AMI to monitor household loads in conjunction with demand side management hardware that could control EV loads by remote switches. These remote switches would be used to control the ON/OFF status of EV outlets, and household loads. Charging is enabled when transformer loading permits the addition of loads and in the case of multiple chargers, staggers them time-delayed throughout the night. This approach requires that AMI technology is implemented to report in short time increments on load conditions on individual households.

The solution proposed here, Fig. 11 assumes that AMI metering will remain primarily an accounting tool for utilities for the foreseeable future. Issues limiting adoption of detailed reporting are related to cost of implementation and resulting ROI, data privacy, handling of data volume, resistance by customers to allow a utility to "see" into their homes past their meters, worries about EMF from meters, etc. These issues will be addressed in due time but proliferation of EVs and the resulting challenges require local solutions. 


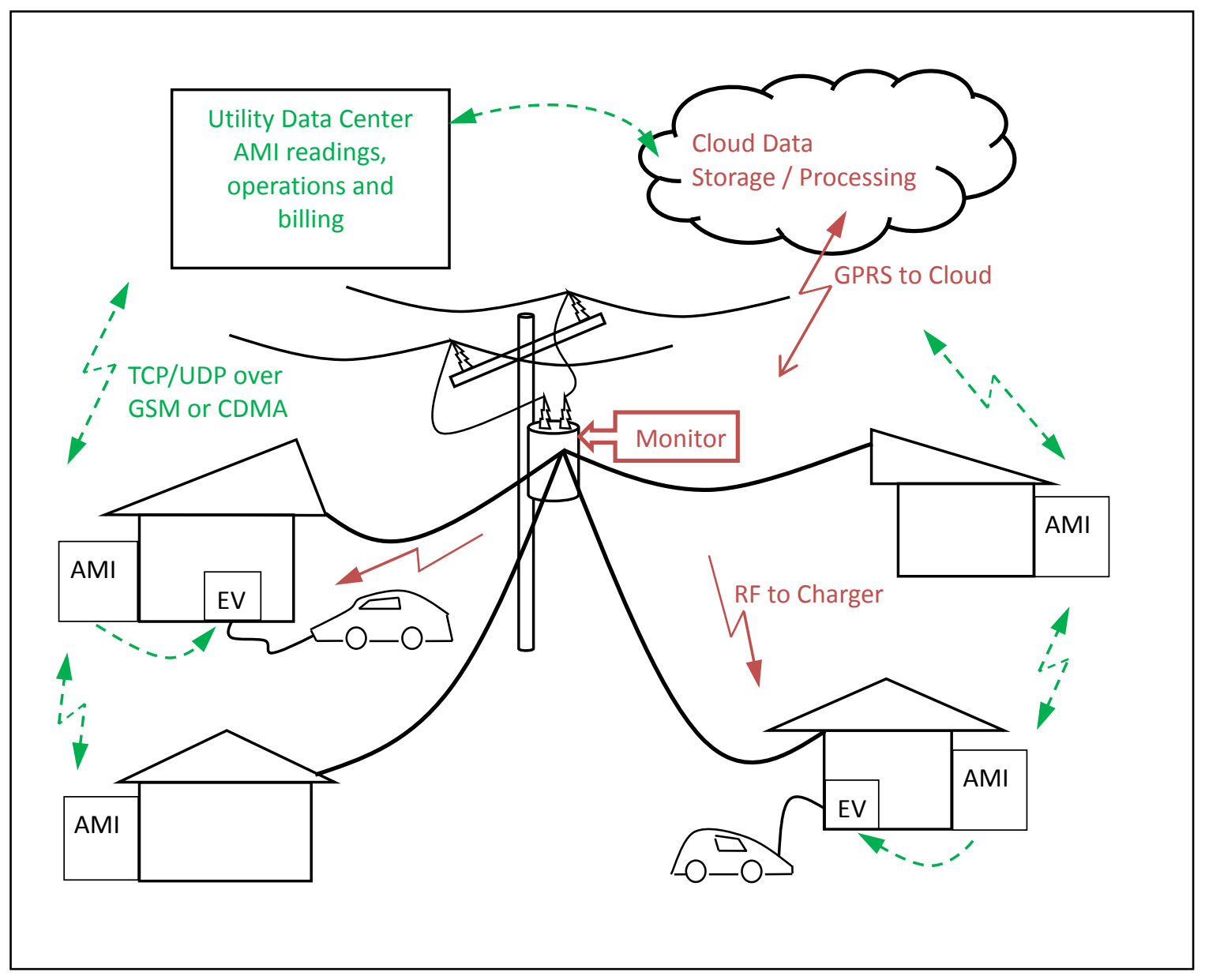

Fig. 11: System level approach to distribution transformer monitoring

\section{Device Description}

A device "Monitor" is to be deployed by attaching it to the outside of the PMDTs near the top of the transformer can that will monitor the top oil temperature through the thinwalled steel. This method of monitoring addresses the issue at its core: distribution transformer protection. It also avoids undue intrusion into homes since temperature data is load and time averaged. The Monitor is powered by converting waste heat from the transformer and collects transformer temperature continuously. It is equipped with a 
GPRS enabled chip set through which accrued data is uploaded once a day directly to a cloud data site for storage and processing.

Local intelligence allows for increased frequency of monitoring if transformer temperature rises above a prescribed level and issuance of alarms should transformer temperature reach critical levels. Another RF transmitter can issue load control commands to throttle down chargers or shed other such enabled loads.

This direct monitoring takes into account local conditions such as weather, wind and exposure that may influence temperature in the transformer beyond just loading and nameplate rating. Detailed data processing in the cloud allows monitoring of each PMDT for loss of life and critical events. A history is stored for each unit and if utility parameters are exceeded the transformer can be scheduled for upgrade for a larger unit. An added benefit of local monitoring and control is that the system doesn't need to comply with NERC and FERC rules since the data stream is not real time and is not integrated into the operation of the power grid.

\section{Monitor}

The monitor is a purpose-build microprocessor $(\mu \mathrm{P})$-enabled data logger that contains all but the thermocouple and thermo-electric generator on one board, Fig. 12. Preliminary research shows the unit can be built the size of a deck of cards.

Power is harvested by two Peltier elements which operate on the temperature difference between two surfaces. The energy generated is sufficient to run the $\mu \mathrm{P}$, whose power requirements are in the $\mu \mathrm{Amp}$ range, and charge $\mathrm{NiMH}$ batteries that store power for infrequent radio communication. 


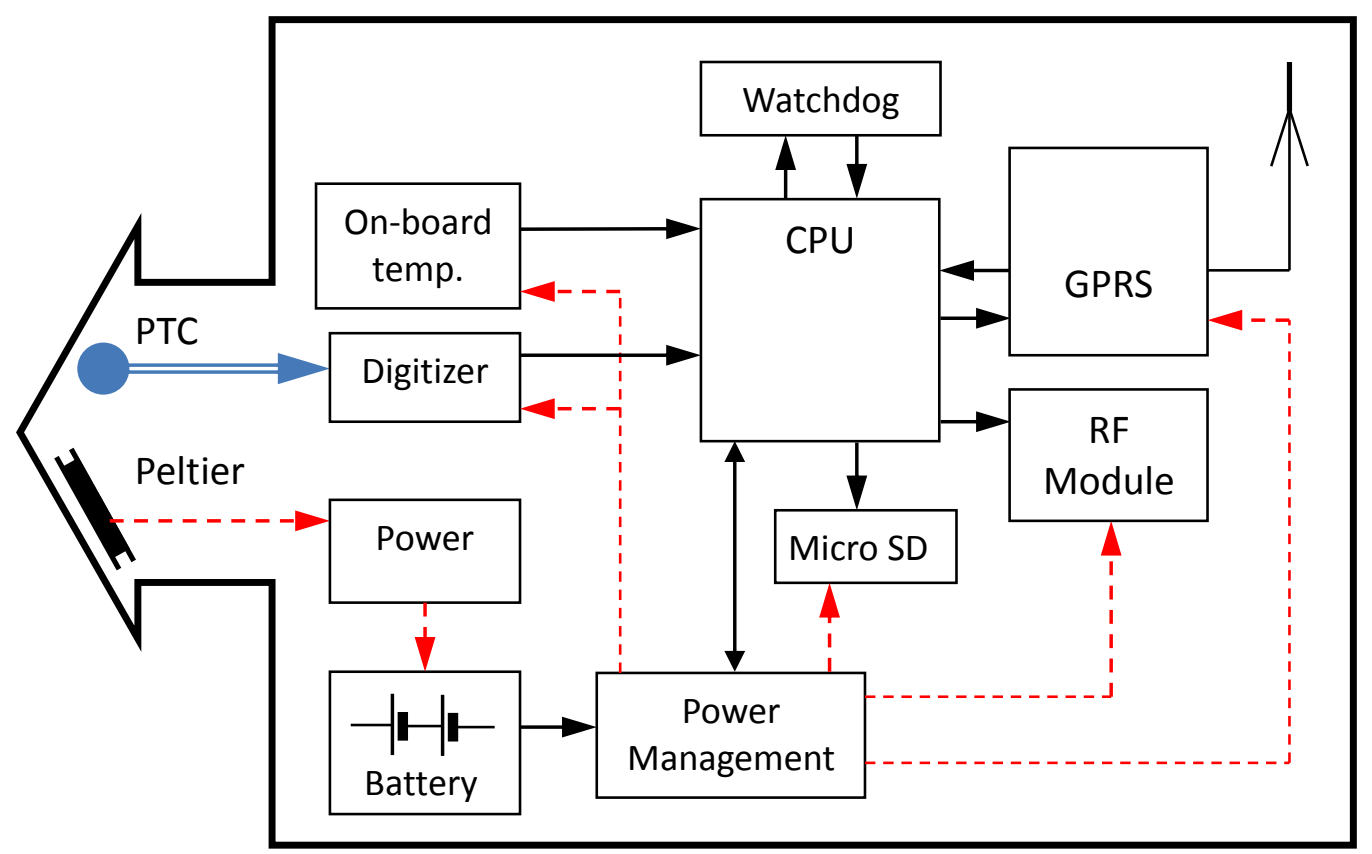

Fig. 12: High level block diagram of Monitor unit

A PTC resistor measures the transformer wall temperature and an SMD digital temperature probe on the PCB measuring ambient temperature provide temperature data input.

The CPU stores executable code and provides intermediate data storage between uploads. It also provides data processing to compare alarm settings, calculate rate of temperature increase and keep time. In case GPRS connections cannot be established an SD card acts as a back-up and bulk storage device.

Since distribution lines are notoriously noisy with switching spikes, lightning surges and harmonics that may interfere with the function of the Monitor, a watchdog timer tracks the $\mu \mathrm{P}$ and GPRS and initiates a reset if they get hung up.

The RF module is for local communication only, with a range sufficient to talk to a receiver-enabled relay that will power down chargers or shed loads. Modern Stationary 
chargers typically provide an external input for the purpose of selecting charge level. Older chargers or vehicle-based chargers that don't provide for this possibility will need to be turned off by cutting power with a shut-off relay. The communications protocol is encrypted and power-limited to protect against unauthorized access. Since the monitor uploads event logs to the cloud as well as data it is feasible to provide an SMS-based message service to notify customers of the action taken.

\section{Cloud Data Processing}

The "cloud" is a modern term for what used to be referred to in the pre-internet days as a mainframe.

The cloud provides rented processing power, storage capacity, back-up facilities etc. that are accessible from any internet-enabled device, Fig 13. There is any number of providers that offer such services such as Amazon, Microsoft, Google, etc.

The advantages cloud computing provides is low up-front cost, scalability, decentralized operation and redundancy among many others. The limitation is internet up-time and crowding that may delay inquiries unless specific steps are taken to protect against such inconveniences.

In general, operation-critical services require dedicated equipment. However PMDT monitoring and data processing is a perfect application for the cloud.

Raw data uploaded from Monitors populates an SQL database. Automated code checks for recent uploads and scans the data for validity. Invalid data that may have been corrupted in the upload process or interrupted uploads will be filtered, as well as data that falls outside of reasonable ranges. 


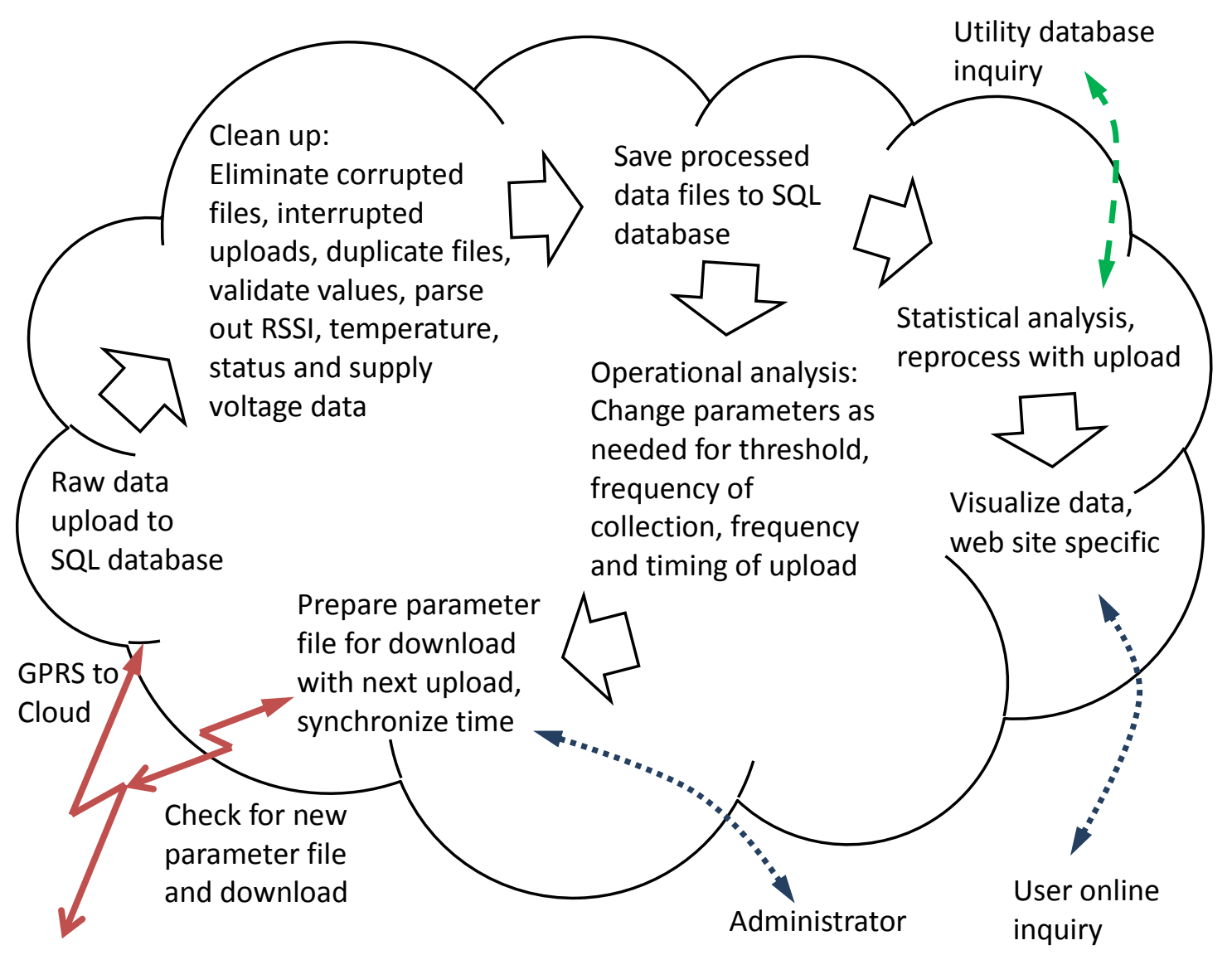

Fig. 13: Cloud Data processing and storage

Monitor status, signal strength and other housekeeping information is stored in Monitorspecific data bases and can generate feedback data that can adjust operational parameters of the Monitor.

The cleaned and parsed transformer data is stored in another SQL database and can be processed with statistical online tools to reduce the data volume to relevant results. The results can then be accessed by the utility and integrated into existing asset management software. 
The same data processed with online visualization tools can be made accessible to customers who may want to educate themselves about how their load profile changes. This portal can serve to educate the public and motivate beneficial behavioral change. Finally, administrators keep track of Monitor health and have the option to adjust functionality of the Monitors by adjusting parameter files that the Monitors check for and download. Parameter files contain information about sampling frequency, temperature sampling threshold, alarm threshold, upload frequency, upload time, data algorithm etc.

\section{Firmware}

The firmware drives the functionality of the monitor and ties together hardware functionality on a component level with command line processing, Fig. 14. The firmware is installed before the Monitor undergoes testing and can not be updated once the unit is in the field. With that in mind it is important to distinguish parameters that will remain constant, such as hardware connections and functionality-related code and parameters that are flexible and can be updated through parameter file downloads.

In order to preserve battery power, raw hexadecimal data is recorded and processing is kept to a bare minimum, only as far as it is relevant to the decision making process driving the logging and uploads.

Parameters that remain constant:

Identity The unique identifier under which each monitor is reporting remains unique. This identity can be derived from the GPRS chipset, the SIM card or a Monitor specific MAC address chip 
Reporting Destination When the Monitor is powered on, it initiates a report to announce its presence on the web, synchronizes its time base with internet time and updates its parameter file.

Battery and Status Track the health of Monitors deployed in the field, reporting of status data has to be uniform across the platform

Parameters that can be changed are as follows:

Time It can be assumed that the internal time base will shift due to environmental factors. For the purpose of labeling data points, a drift of several minutes over a twenty four hour period is acceptable but Time needs to be synchronized every time the Monitor connect to the internet.

Alarms Transformer over temperature alarms have to be flexible to accommodate the various types of transformer construction. i.e. $55^{\circ} \mathrm{C}$ rise or $65^{\circ} \mathrm{C}$ rise

Temperature Rise Rate To account for the dynamic nature of transformer heating, temperature rise rate is more telling than just temperature since it indicates that heating has already taken place and is now manifesting in rising temperature. Larger transformers will have a larger lag time, expressed by $\tau_{o}$ and $\tau_{H}$ so the temperature rise rate as a decision criteria has to be lower.

Upload Time To get reliable uploads without dropped calls or interference, upload time can be optimized such that it falls into a time period where there is little traffic on the primary cell tower or beneficial atmospheric conditions.

Upload Frequency How often is the data uploaded to the internet? If upload frequency is higher than once a day this parameter supersedes Upload Time 
Sampling Threshold Below this temperature threshold the Monitor checks transformer temperature once a minute.

Sampling Frequency How often does the $\mu \mathrm{P}$ wake up to check on transformer temperature once the temperature threshold has been exceeded?

Repetition Cycle The parameters within the repetition cycle should be adjustable to optimize communication with the particular network. 


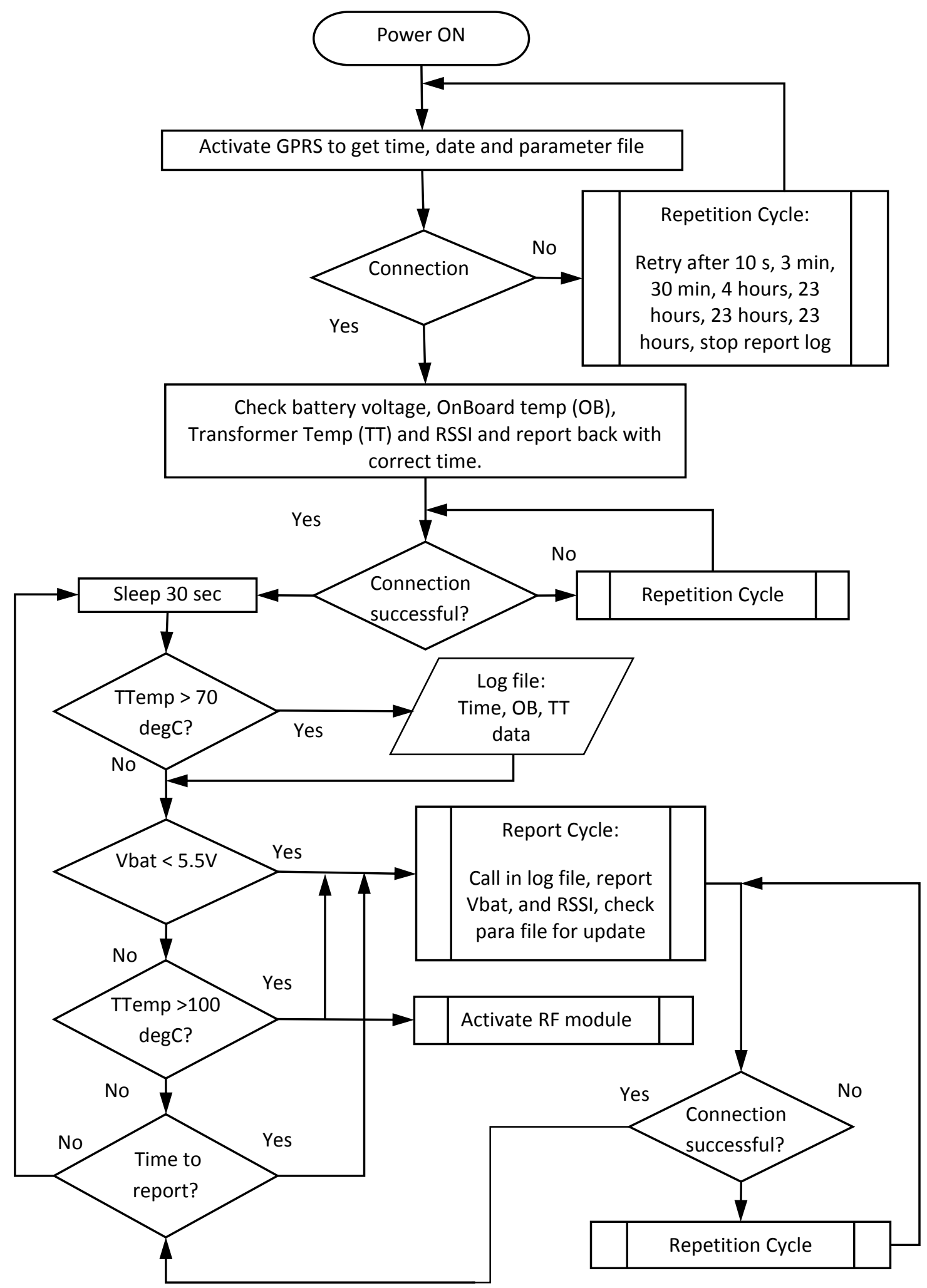

Fig. 14: Firmware Flowchart 


\section{Transformer Monitoring Test Station}

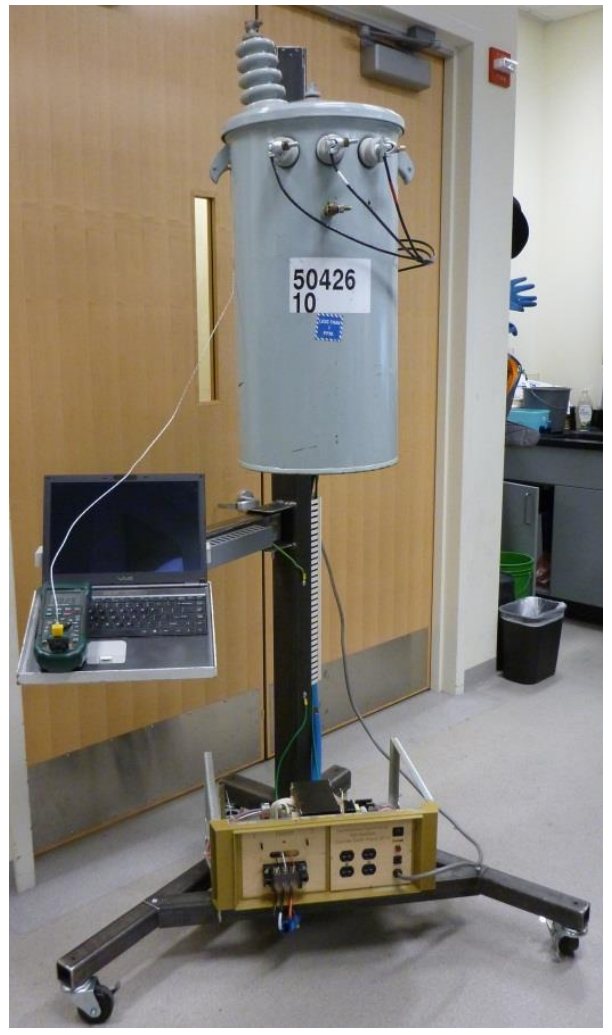

Fig. 15: Primary wiring of Transformer Monitoring Test Station

In order to develop and verify the distribution transformer monitoring, a test station was built. Test Station consist of an empty distribution transformer can mounted on a mobile platform including an instrument tray, power supply and controls, Fig 15. It serves the purpose of providing a controlled test set up for distribution transformer monitoring equipment. On the vertical riser, a $25 \mathrm{kVA}$ distribution transformer can is mounted and equipped with two heating elements to simulate base load and overload conditions in the transformer. In order to provide safe operation the heating elements are powered from a 1500 VA step down transformer with two $26 \mathrm{~V}$, potential free secondary windings, Fig. 16. 
Heating element 1 provides $200 \mathrm{~W}$ diffuse heating at the lower end of the can to reach temperatures of $60{ }^{\circ} \mathrm{C}$ along the left hand side of the can.

Heating element 2 provides $330 \mathrm{~W}$ of surface contact heating in an 8 " circle centered 9" below the rim on the right hand side to reach $85^{\circ} \mathrm{C}$.

When both heating elements operate concurrently a maximum temperature of $100{ }^{\circ} \mathrm{C}$ is reached in approximately 50 minutes, depending on air velocity in the room.

\section{Schematics}

\section{Primary}

The primary circuit in Fig. 16 provides a power main switch that energizes the transformer and turns On the utility outlets on the face plate as well as the 12 VDC power supply for the controls. A 15 A resettable fuse protects the wiring from accidental overloads as well as short circuits. An indicator confirms presence of primary voltage.

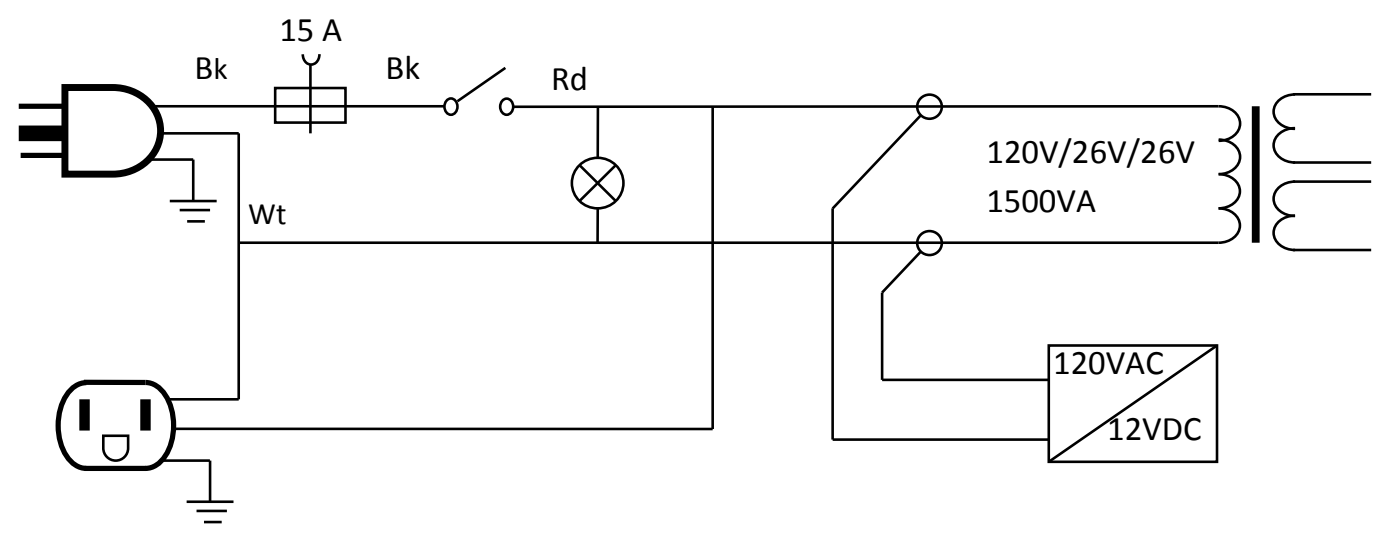

Fig. 16: Primary wiring of Transformer Monitoring Test Station 


\section{Secondary}

The secondary circuit in Fig. 17 provides power to the heating elements. Relays one and two can operate individually or in conjunction with one another to provide up to $500 \mathrm{~W}$ localized heat.

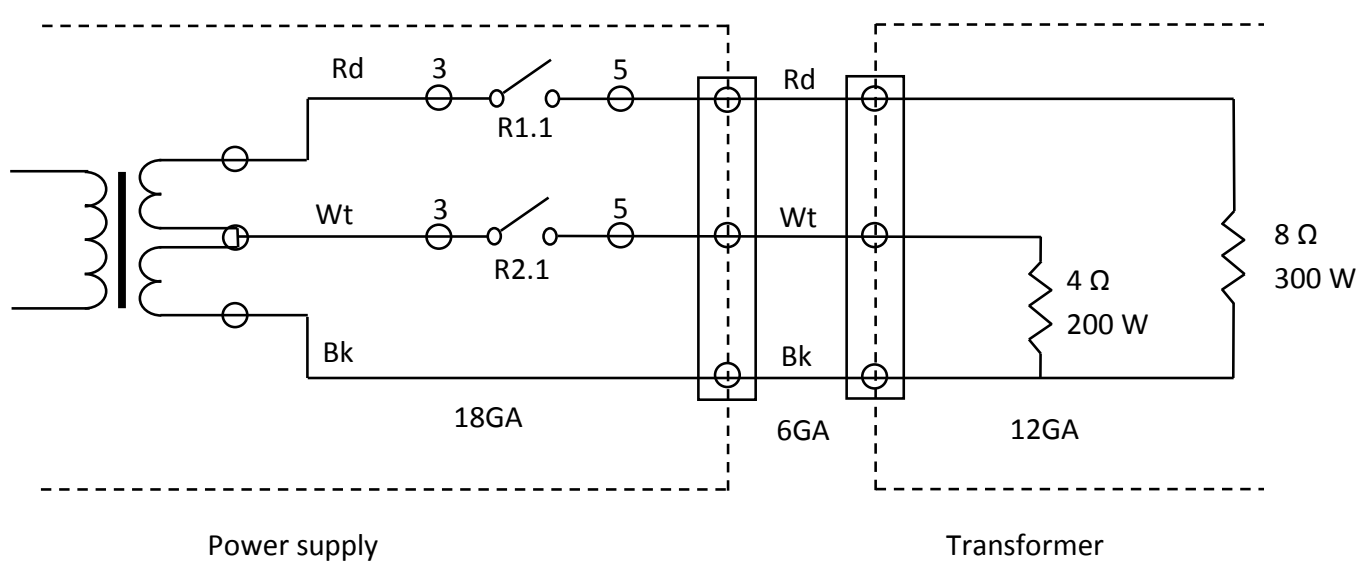

Fig. 17: Secondary wiring of Transformer Monitoring Test Station

\section{Control}

At present the controls are limited to independent relays that control the resistive heaters. No temperature, profile or time controls are provided, and there are no over temperature shut off switches, Fig 17, Fig 18. The transformer reaches a steady state surface temperature at $100{ }^{\circ} \mathrm{C}$ in the lab.

A DIN rail provides room for expansion for PID controllers that would add ramp and hold characteristic. The final build as of the writing of this paper is shown in Fig. 19. 


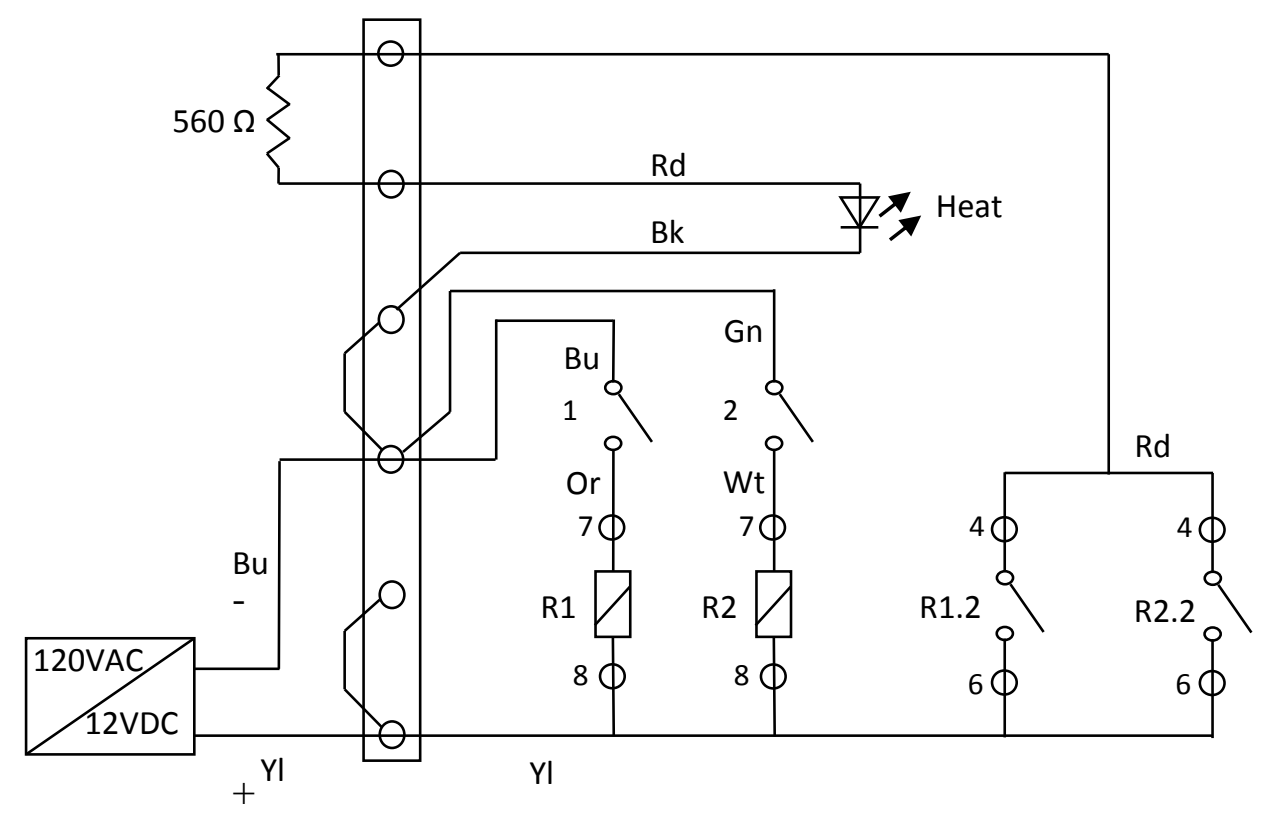

Fig. 18: Control schematic of Transformer Monitoring Test Station

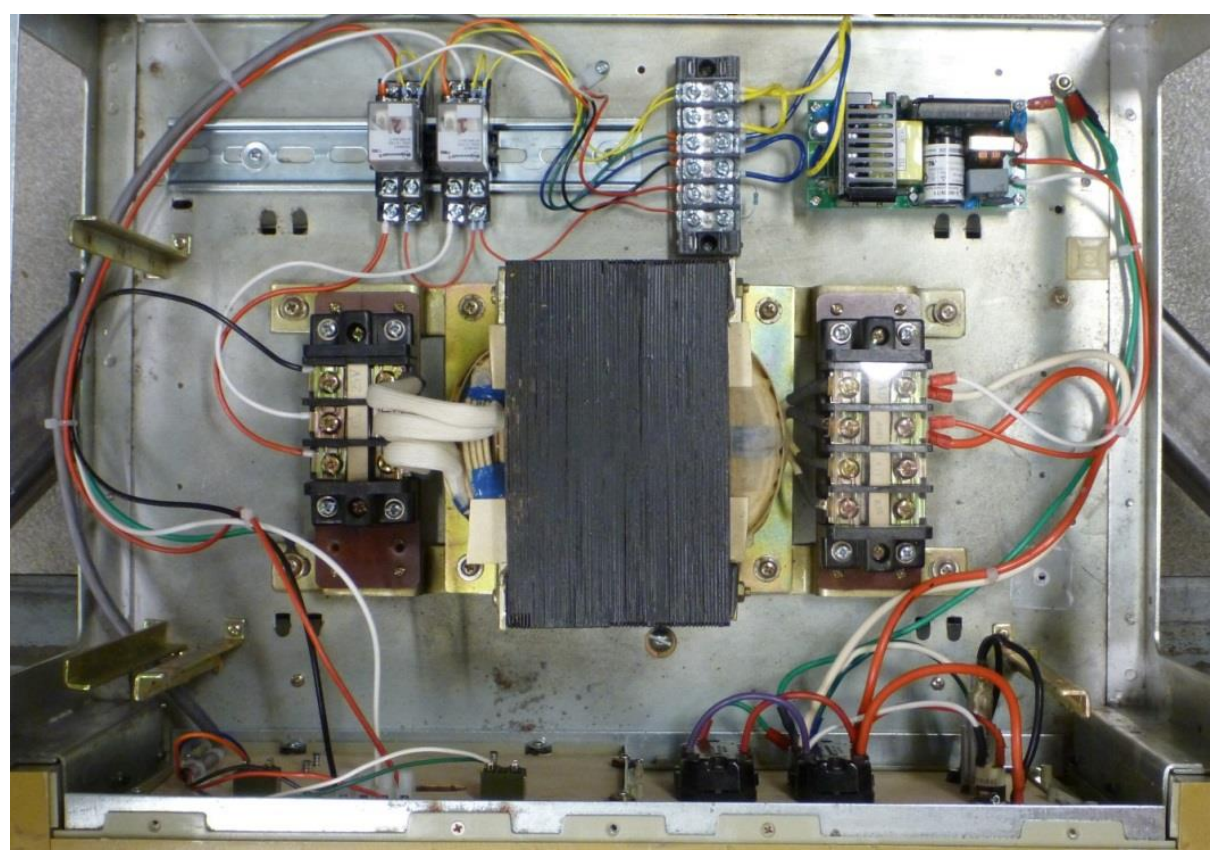

Fig. 19: Final Assembly of Transformer Monitoring Test Station 


\section{Demand Response Load Control}

The second part of the distribution transformer test station is the Demand Response Load

Control. This test set bed will acts as a demonstration / test platform / educational tool to test communication hardware and software to be implemented with the distribution transformer monitor, Fig 19. The display is a simulated electric vehicle with LED indicators for Level 2 and Level 1 charging as well as Off. The set up contains a $12 \mathrm{~V}$ and 3.3V DC voltage source as well as a high impedance transistor relay driver. Relay contacts can with $240 \mathrm{VAC} / 15$ A capacity can drive supply voltage directly to a Level 1 charger or activate larger load relays. 

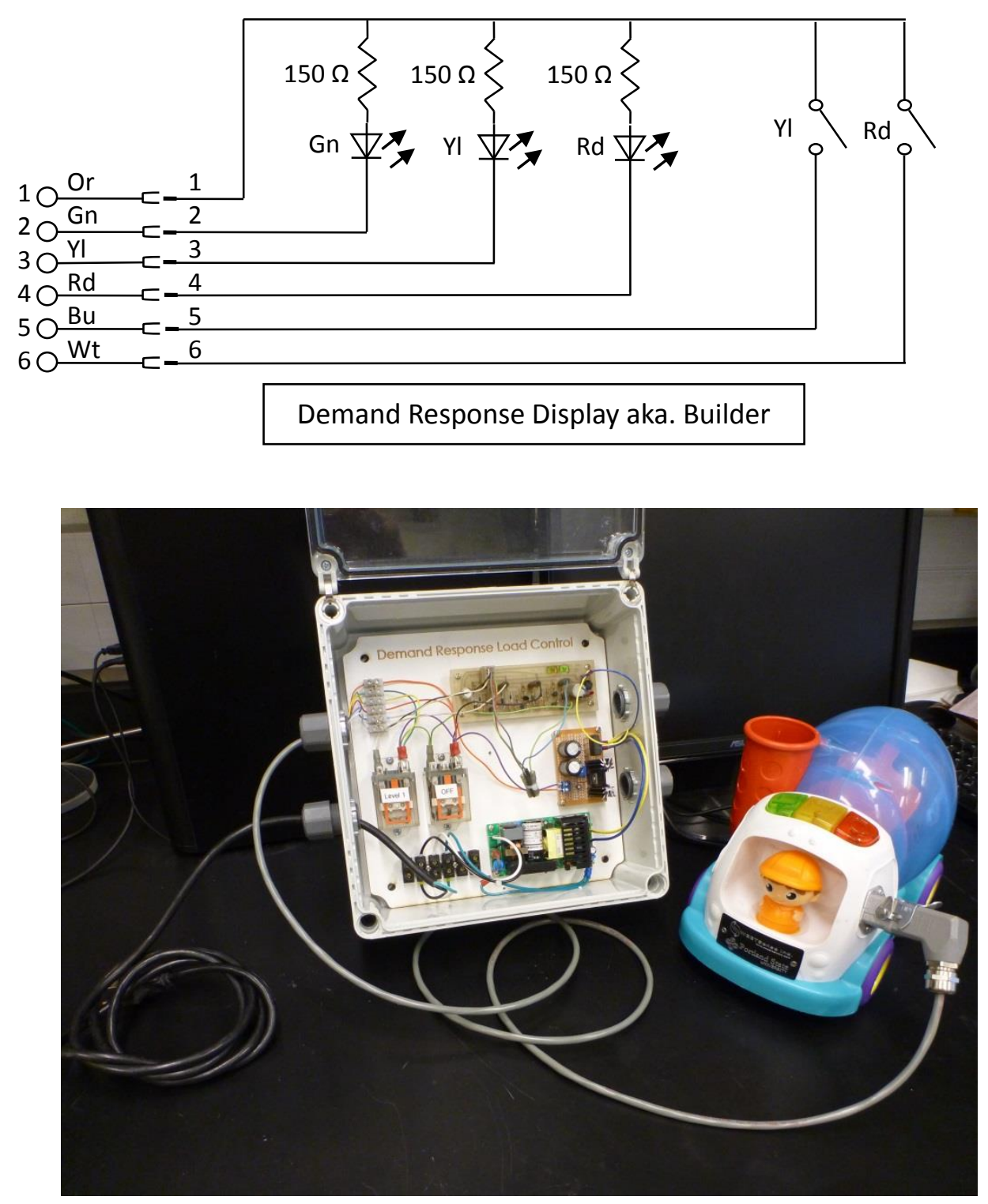

Fig. 20: Schematics and Assembly of Demand Response Load Control 


\section{Distribution Transformer Monitor}

The Distribution Transformer Monitor (DTM) pictured in Fig. 21 is based on a hardware solution developed by the SWEETLab at Portland State University with outside partners that has found distribution in monitoring NGO projects in the developing world. A functional description of its web environment has been published in Remotely Accessible Instrumented Monitoring of Global Development Programs: Development and Validation available online [19], although the hardware is a new development.

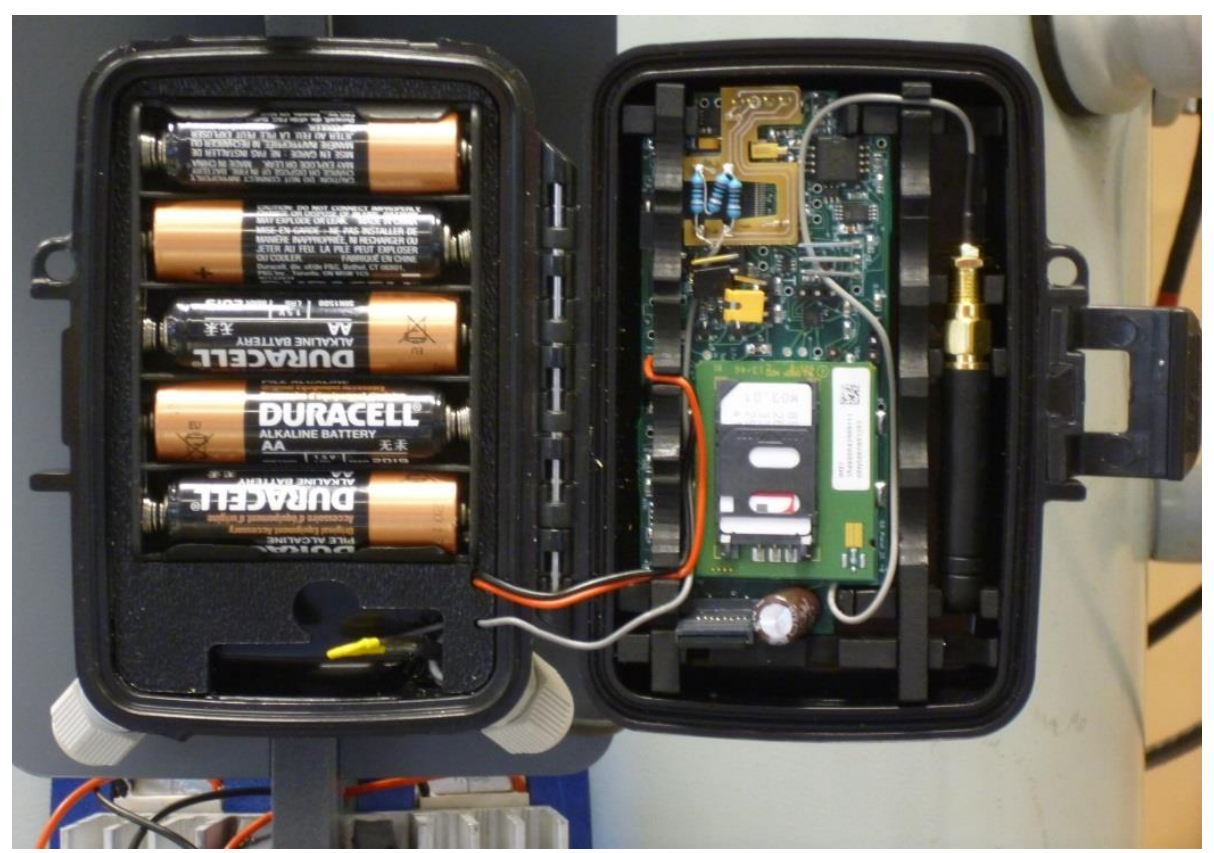

Fig. 21: Distribution Transformer Monitor with modifications

"The smart-sensor technology is designed to have a low power profile, while maintaining high resolution data logging capabilities. Currently, data loggers have a tradeoff between frequency of sampling and logging, and energy consumption. However, for these applications infrequent sampling and logging (anything less than every second), can result in missing usage events that are of interest. The SWEETSense ${ }^{\mathrm{TM}}$ technology addresses this issue by sampling at a comparatively high rate, between several times a minute and many times a second, while only logging and relaying the data when a predetermined change in the parameter is sampled. This thereby minimizes power consumption and allows high resolution 
logging of usage events while running off of compact batteries for a targeted minimum of six months.

The SWEETSense ${ }^{\mathrm{TM}}$ combines commercially available front-end sensors, selected for specific applications including water treatment, cook stove, sanitation, infrastructure or other applications, with a comparator circuit board that samples these sensors at a reasonably high rate. The comparator boards monitor the sensors for trigger threshold events that start and end periodic local data logging. The comparators sample the sensors frequently, and the output is fed into a low power microcomputer chip where the relative time that the parameter change occurs is logged. Logging continues until the parameter returns to a predetermined baseline. The stored events are coded to reduce the amount of data, and thereby the amount of energy required for transmission.

One or more times per day, the comparator board relays logged data events to the internet via Wi-Fi or GSM cellular phone technology. Data processing is enabled on an internet based software program (www.sweetdata.org), where the primary algorithms are stored. The internet based program also contains manually and automatically updated calibration files that are periodically and automatically relayed back to the local sensor boards. The innovations in this invention include the processes used to enable long duration operation with high resolution data logging while operating on simple, small batteries; the use of customized and remotely updatable threshold trigger events; and the distributed data processing load between the local sensors and the internet." [20]

To realize the distribution transformer load monitor a SWEETSense ${ }^{\mathrm{TM}}$ monitor was equipped with a $1 \mathrm{k} \Omega$ thermistor in a bridge configuration that feeds into an $\mathrm{AD}$ convertor. A mechanical mounting system was devised that allows for the monitor assembly to be dispatched with a Hot Stick to the side of a transformer utilizing one of the bilateral lift hooks and strong permanent magnets that hold the monitor securely in place, Fig. 22. The permanent magnets are also the hot-site contact surfaces for the Peltier elements. This energy harvesting provides approximately $10 \mathrm{~mW}$ of power to the monitor batteries when the transformer surface reaches $60{ }^{\circ} \mathrm{C}$ above ambient. 

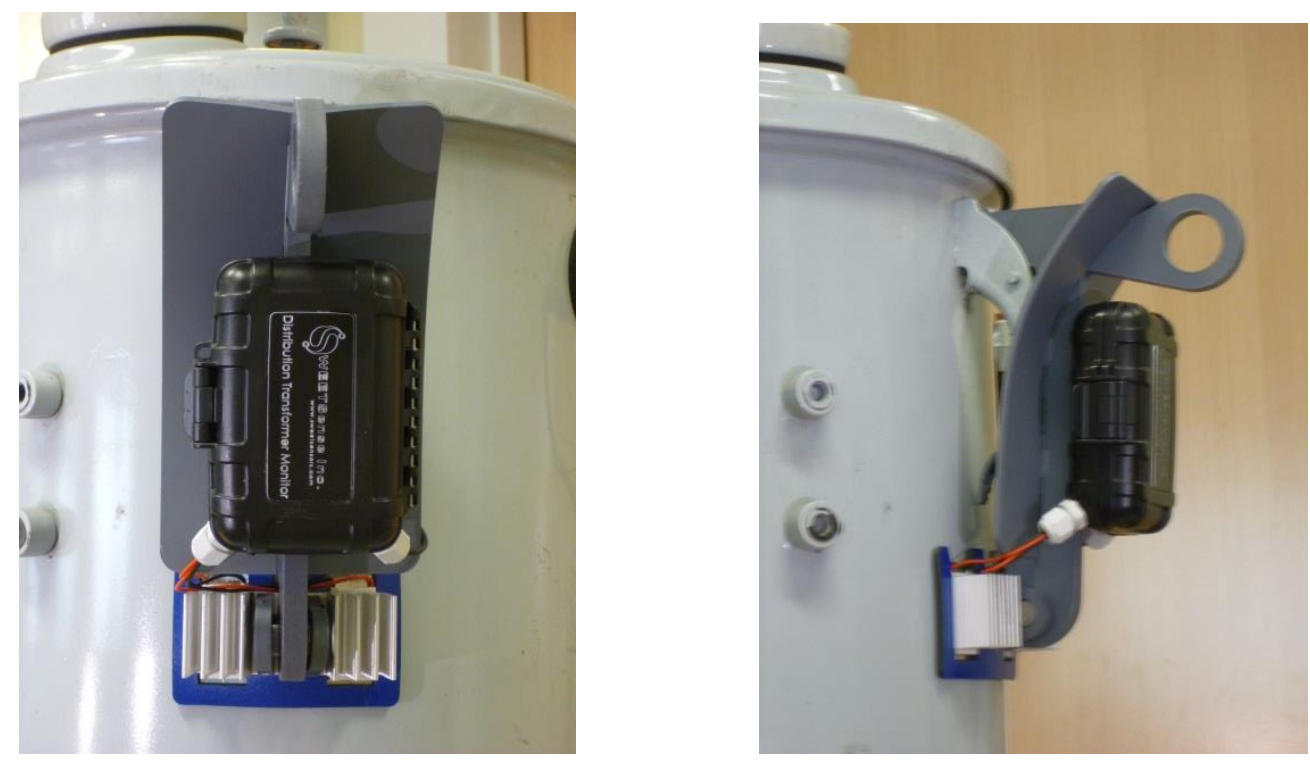

Fig. 22: Distribution Transformer Monitor mounting

The mounting system also provides thermal shielding from the transformer while maintaining convective cooling. The electronics board and batteries are housed in a modified waterproof, UV stabilized, polycarbonate housing, itself rated at IP67. Two bushings provide access for harvester and thermistor wiring. To accommodate the thermistor input, a daughter board had to be designed to interface with the SWEETSense ${ }^{\mathrm{TM}}$ board, Fig. 23. The daughter board serves double duty as an RF shield to the micro-processor to protect from antenna radiation. To minimize noise on the AD circuit, two capacitors were added on the power and signal line. DipTrace was used to draw the schematic, create a layout and Gerber and NC files to produce a prototype on the LPFK router in the PSU EPL lab. SMD capacitors were soldered in the reflow oven. The bridge resistors are of axial type, metal wound, $1 \%$ tolerance. 

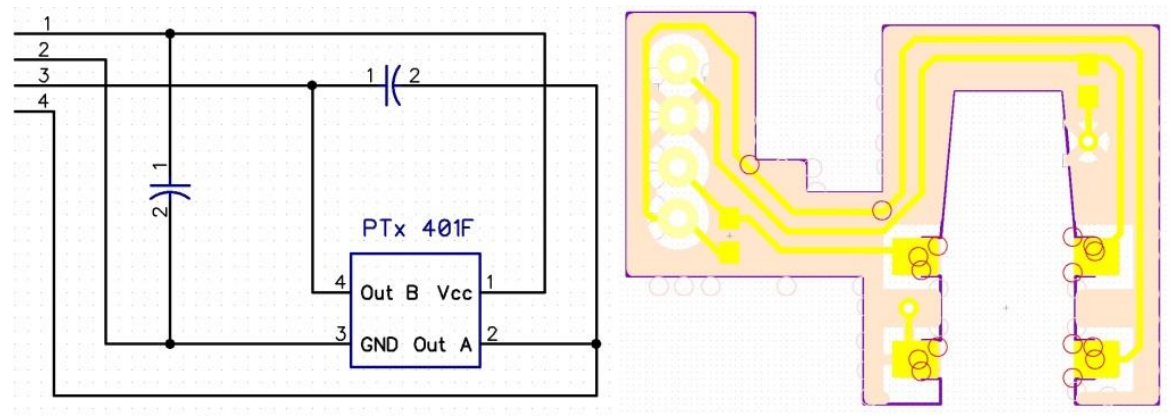

Fig. 23: Daughter board Layout for thermistor bridge

Due to z-axis space constrains, the resistors have to be embedded into the daughter board rather than through-hole mounted. The overall package leaves less than $0.5 \mathrm{~mm}$ vertical clearance in the polycarbonate case. The final product can be seen in Fig. 21.

\section{Validation}

Several validation steps were undertaken in the lab with the help of the Distribution Transformer Test Station. Thermal shielding of the electronics package was validated using infrared images during hour-long test runs, Fig 24. A Flir SC660 infra-red camera was used to study heat radiation and distribution. Infra-red imaging temperature is a derived quantity based on an assumed emissivity of the surface the camera is receiving. To validate the emissivity of $\varepsilon=0.83$ a thermocouple in conjunction with a CenTech P98674 DMM was used to take spot measurements. Although the outside surface of the transformer reaches up to $100{ }^{\circ} \mathrm{C}$ the heat shield and passive convective cooling keep the electronics enclosure within $3{ }^{\circ} \mathrm{C}$ of ambient temperature. 


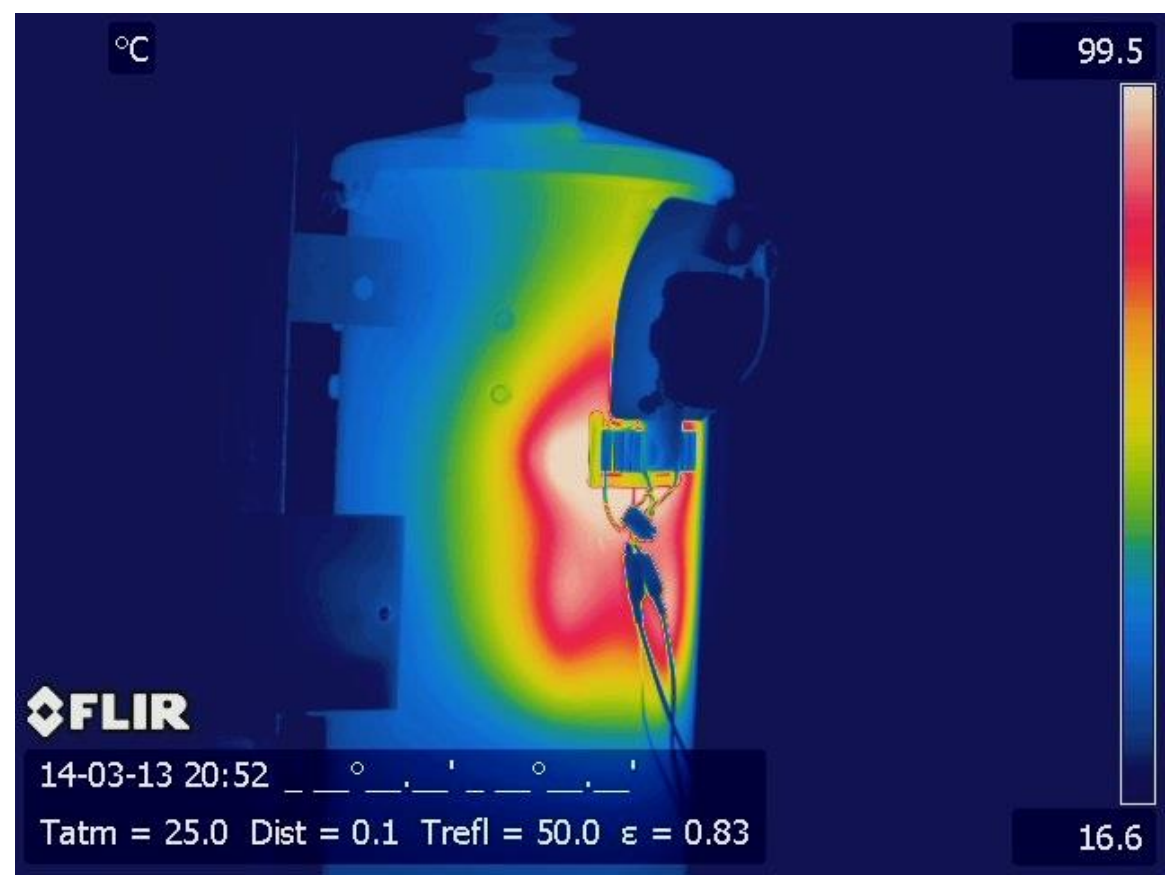

Fig. 24: Transformer Monitor Heat Shielding

Another validation involved the power output of the Peltier elements. Two $20 \mathrm{x} 40 \mathrm{~mm}$ elements with 62 junctions each were selected for the assembly and assessed for power delivery, individually and in series. The Peltier elements are each bonded to a 1 x $2 \times 1 / 16 "$ permanent magnet on the hot side. On the cold side the Peltier elements are bonded to a common aluminum heat sink of 35 (h) $\times 80$ (w) mm with 23 × 2 mm tapered fins. The heat sink is shaped to conform to the radius of the transformer can. The Peltier elements and magnets however are flat, thus heat transfer occurs along a contact line in the longitudinal direction roughly in the middle of the magnet. No heat transfer paste was used, the assumption being that the treatment would not last when exposed to the elements. Radiative heat transfer covers the entire surface of the magnets. A $1 / 8$ " thick PVC bezel was inserted between the magnets and the heat sink to prevent radiative heat transfer to the heat sink. 
Power demands of the monitor is in the $\mu$ Watt range during sleep stages. During temperature sampling cycles, demand rises to less than $5 \mathrm{~mW}$. However when transmitting, the GPRS radio chip may draw as much as 2 Amps in short bursts and up to half that during transmit. Transmit power is optimized automatically and depends on signal strength which is a function of distance to tower and environmental conditions. Thus the energy demand is primarily a function of frequency of uploads and duration of upload time, which in turn is a function of quantity of data gathered. For the purpose of assessing the harvester the following assumptions were made: Two uploads per 24 hour time period at $1 \mathrm{Amp}$ and 1 minute duration at a nominal system voltage of $5 \mathrm{~V}$, negligible energy consumption the rest of the time. Boost conversion, NiMH battery charging and discharge efficiency is assumed at 50\% total. Thus energy generation of $330 \mathrm{mWh}$ is required over a 24 hour time period to maintain fully charged batteries. To maintain the batteries at full charge, an average charge energy of $14 \mathrm{~mW}$ is required; $24 \mathrm{~h} \times 14 \mathrm{~mW}=336 \mathrm{mWh}$. The single element configuration showed insufficient output at $2.5 \mathrm{~mW}$ in purely convective mode. However when forced air cooling was introduced, turbulent air flow at approximately $1 \mathrm{~m} / \mathrm{s}$ 'light wind' conditions the power output increased by almost $50 \%$. The jump is evident one hour into the test in Fig. 25; power output reaches a steady-state at $3.5 \mathrm{~mW}$ thirty minutes after forced air cooling is introduced. The Peltier element was loaded with $10 \Omega$. 


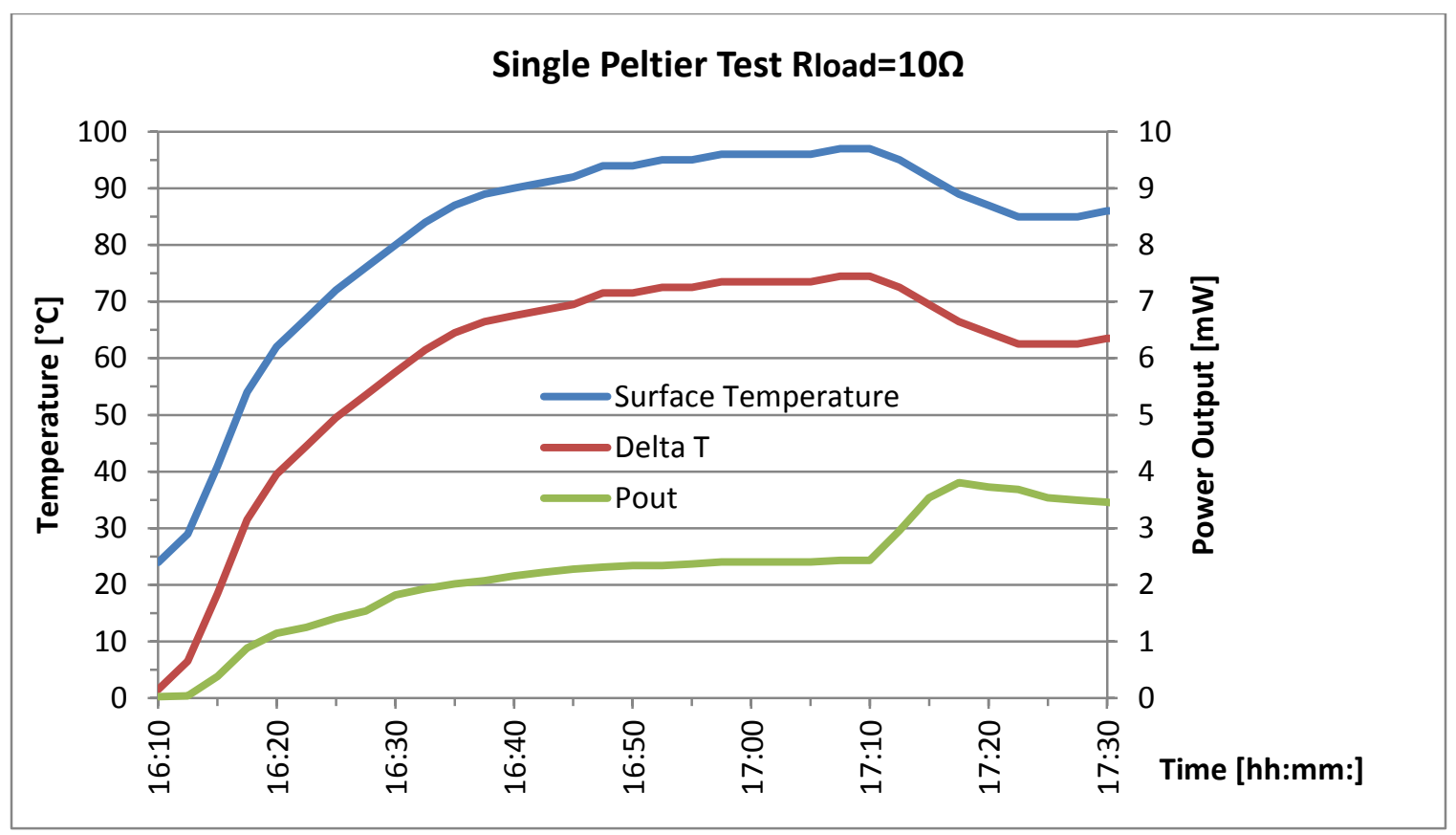

Fig. 25: Single Peltier test with forced air cooling at one hour 3/14/2014

Figure 26 shows a one hour test with two Peltier elements in series under purely convective cooling conditions with a $10 \Omega$ load. It can be seen that a charge of $8.3 \mathrm{~mW}$ is present at a $\Delta \mathrm{T}=45^{\circ} \mathrm{C}$. In 'light wind' conditions this would be sufficient to maintain battery charge. 


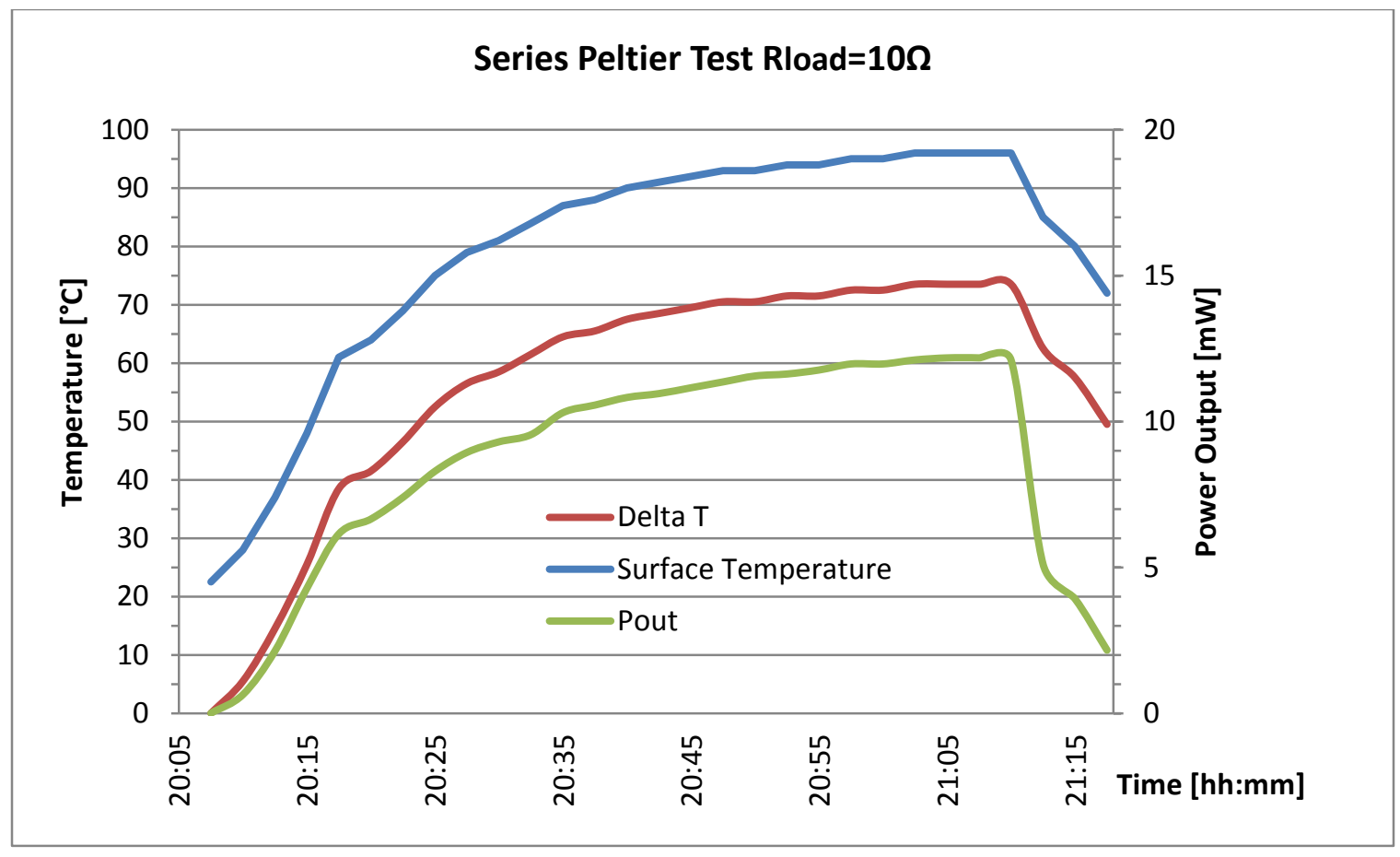

Fig. 26: Double Peltier test for one hour 3/13/2014

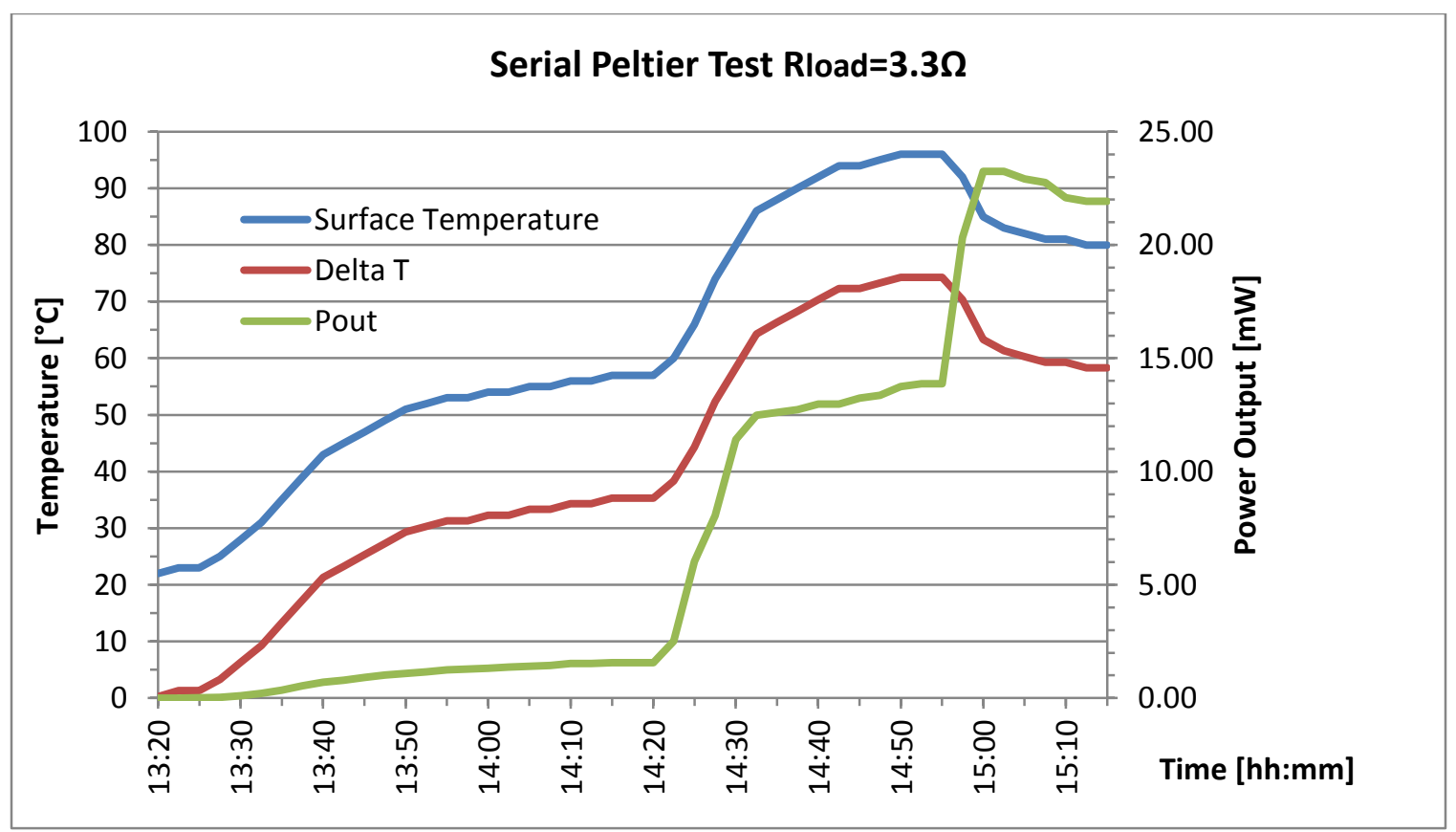

Fig. 27: Double Peltier test $R_{\text {load }}=3.3 \Omega 3 / 15 / 2014$ 
The third test, Fig. 27, shows a series arrangement of Peltier elements but with a load of 3.3 $\Omega$. Again sufficient charge of $8.3 \mathrm{~mW}$ is generated at a $\Delta \mathrm{T}=45^{\circ} \mathrm{C}$ but rises to $22 \mathrm{~mW}$ when 'light wind' cooling is introduced. This variable source impedance is driven by $\Delta \mathrm{T}$ between the hot and cold side. [21]

Whether this temperature gradient can be maintained as an average over an extended time period remains to be seen. Through mechanical optimizations with enhanced contact surfaces and heat sink dimensions, it will be possible to generate sufficient energy to maintain a full battery charge indefinitely. New, fully-charged NiMH 2450 mAh batteries have enabled over 400 uploads in previous experiments.

Validation of data correlation was conducted by overlaying the uploaded temperature recordings with the timed profiles gathered in the lab. Since the monitor uploads raw uncalibrated data only the time correlation was assessed. Calibration is accomplished by online data processing.

The following data is uploaded with each cycle: Battery voltage, RSSI - radio signal strength during upload, On-board digital temperature and raw analog values.

The file is uploaded as a text file to the monitor address: http://www.sweetdata.info/data/AFRIDEV/AFRIDEV_D434A3.txt with Afridev the original device type and D434A3 its unique identifier. A sample file excerpt is attached in the addendum. The data is separated and checked for validity and duplication and then stored in an SQL database. From there the data is available for calibration, filtering, statistical analysis or online visualization. The monitor data set is displayed on www.SWEETData.org. Each application web page can be configured with various graphical display options such as bar graphs, dials, line charts as well as GPS 
driven mapping and interactive visualization tools. The page can also be linked to service providers that send out SMS, e-mail, Twitter, facebook and other social media notifications.

After logging into the project page the following data is displayed. Figure 28 displays the logged data since the board was turned on $3 / 11 / 2014$. The time base is linear but not continuous since the monitor does not log data unless a change on the analog input is detected. Depending on the application, visualization can be formatted to meet a specific purpose; the last heating cycle clearly corresponds to events recorded in Figure 27.

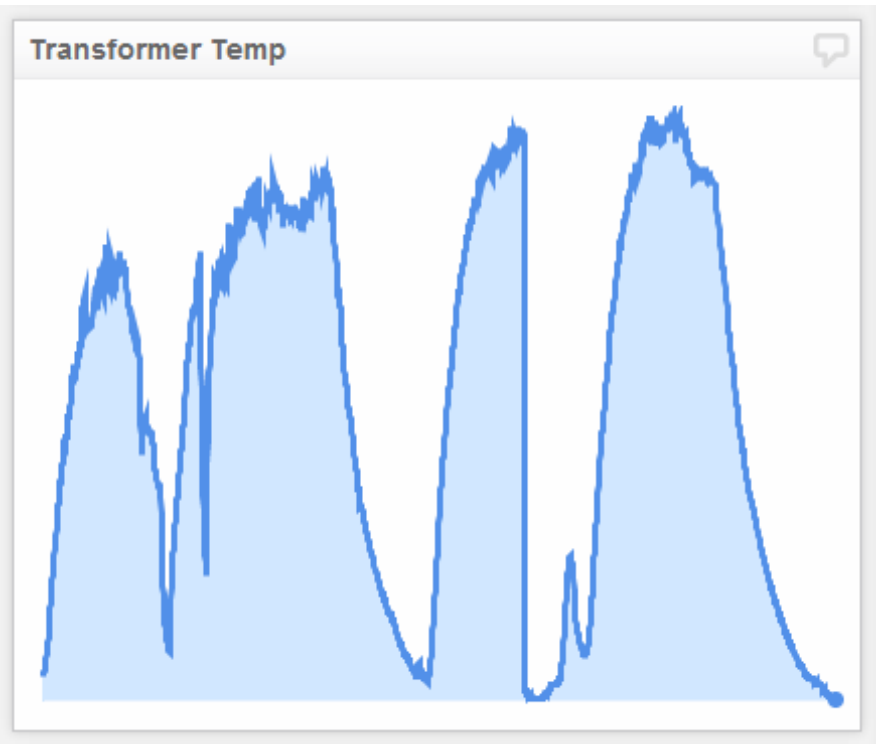

Fig. 28: Uploaded analog data logged from 3/11/2014 to 3/13/2014

The on-board temperature in Fig. 29 is recorded with a digital temperature chip. Since the monitor is kept indoors the temperature is relatively stable. Appropriate vertical scaling could reveal a higher resolution. The vertical bars represent lack of data as temperature acquisition is suspended during uploading. The bars also reflect an update in the 
configuration file where the upload frequency was changed from 24 hour reporting to a two hour reporting cycle.

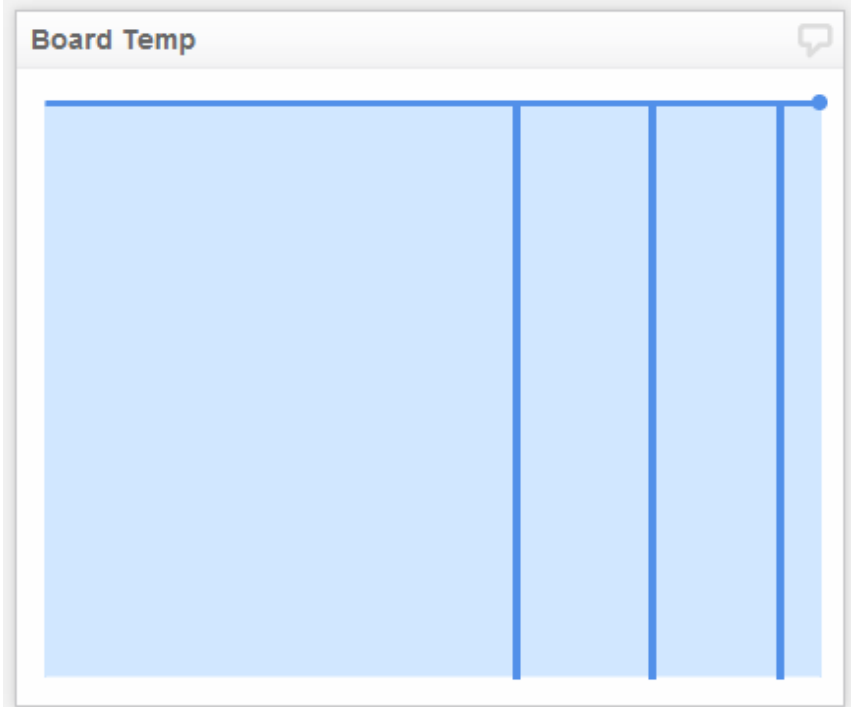

Fig. 29: Board temperature from 3/11/2014 to 3/13/2014

These data sets are as yet uncalibrated. Calibration will require correlating the structured observations in the lab with uploaded data and appropriate scaling for display.

Data from the monitor is subject to time delays. In normal operation the data is uploaded at prescribed time intervals as defined in the configuration files, typically once every 24 hour. Once the data is uploaded it is processed in batches every few hours; for historic record keeping, such as transformer life assessment that is without consequence. If operational data is needed, such as transformers reaching excessive temperatures, alarms can be set that prompt the monitor to trigger an instant report. Future implementations will trigger direct RF links to thus equipped relay to initiate demand response load control. 


\section{Cost}

Preliminary research shows that these monitors can be built for under \$200.- with a monthly cost of operation around $\$ 3$ to 5.- for data plans depending on whose cellular network is utilized. Data processing as outlined has been demonstrated by SWEETSense ${ }^{\mathrm{TM}}$, which provides turn-key yet customizable solutions to clients. Due to the relatively low volume of data, online data storage and processing are minimal. The return on investment for monitors is in savings from the extended life of distribution transformers, [18] improved reliability in customer service and higher efficiency in distribution by operating transformers at higher efficiencies. However, without field trial these factors are hard to enumerate. Additionally by providing clients with access to aggregated data the monitor infrastructure provides the opportunity for public outreach work and information. Therein lies the possibility to influence customer behavior. Monitoring services represent an economic opportunity for affiliated service companies that could develop a business model on a pay-as-you-go base. 


\section{Evolution}

The distribution transformer monitor can be demonstrated to record and upload temperature data. Implementation of a wireless communications link between the monitor and the demand response load control is the obvious next step. Clearly the demand response load control can evolve to a web based application that pulls down data from the cloud by monitoring the transformer status utilizing Ethernet services. Several products already exist on the open market that share this functionality such as Cooper Industries Load Control Switch LCR-6600, a WiFi enabled load relay that can be configured with existing home automation systems such as X10, Insteon, Evolve and others. The design has to be tested outdoors on real transformers to check for interference from EM radiation and line noise.

Durability and suitability of the materials used has to be assessed for long term outdoor exposure. It is expected that this initial design will need to undergo modifications. Specific tests to be conducted involve wind tunnel testing to make sure the Monitor attachment is secure, assess if the internal components can withstand electro-magnetic and electro-static fields present around the transformer. Measuring temperature rise in the enclosure in full sun exposure as well as assessing UV deterioration of the enclosure itself is needed. Performance in cold temperatures will have to be assessed as well. 


\section{Conclusion}

The proliferation of electric vehicles has the potential to disrupt the traditional way by which pole mounted distribution transformers have been dimensioned, deployed and

operated. New installations will have to take into account the likelihood of EV ownership and size transformers accordingly. Legacy equipment presents a particular problem since transformers sized for moderate load growth a long time ago will be unable to accommodate EVs without some intervention. Temperature as the most critical factor in transformer life as well as failure will need to be monitored in real-time. The proposed device monitors distribution transformer top oil temperature and reports data to cloud based servers. It also initiates load shedding should the transformer be in danger of overheating. Load shedding is accomplished autonomously by RF controlled relay that throttle chargers or shut them of altogether until such time that the transformer returns to acceptable operating conditions.

The monitoring does not rely on existing utility infrastructure but uses cloud data processing and storage giving it the flexibility for rapid deployment and scaling. The cloud can intersect with utility information and asset monitoring systems as well as customers on internet based portals. It does not infringe on utility turf, nor on customer privacy.

Set up and deployment of monitors does not require service interruption and can be accomplished with a hot stick. Failure of monitors will lead to loss of monitoring but will not damage equipment. 


\section{$\underline{\text { References }}$}

[1] US Department of Energy. (2013, March 7). Frequently Asked Questions: How much electricity does an American home use? [Online]. Available URL:

http://www.eia.gov/tools/faqs/faq.cfm?id=97\&t=3, Mar. 192013

[2] US Department of Transportation, Federal Highway Administration. (2011, April 4). Average Annual Miles per Driver by Age Group. [Online]. Available URL: http://www.fhwa.dot.gov/ohim/onh00/bar8.htm, Apr. 42011

[3] Harlow. (2013, November 10). Distribution transformer. [Online]. Available URL: http://en.wikipedia.org/wiki/Distribution_transformer

[4] Z22. (2012, August 5). Cutaway of a pole mounted distribution transformer [Online]. Available URL: http://en.wikipedia.org/wiki/File:Pole_mounted_singlephase_transformer_cutaway.jpg

[5] A. Elmoudi, M. Lehtonen, H. Nordman. "Thermal Model for Power Transformers Dynamic Loading." IEEE International Symposium on Electrical Insulation, Toronto, Canada, 2006.

[6] IEEE Guide for loading Mineral Oil Immersed Transformers, IEEE Standard C57.19., 1995.

[7] E. Simonson. "Transformer Ratings and Transformer Life." IEEE Colloquium on Transformer Life Management, 1998, pp. 7/1-7/6.

[8] J. Parmar. (2011, August 27). "Difference between Power Transformer and Distribution Transformer." [Online]. Available URL: http://electrical-engineering-portal.com/differencebetween-power-transformer-and-distribution-transformer

[9] P.K. Sen, et al. (2011, February). "Transformer Overloading and Assessment of Loss-of-Life for Liquid-Filled Transformers." [Online]. Available URL: http://www.pserc.wisc.edu/documents/publications/reports/2011_reports/Sen_T25_Final_Report_Feb_2011.pdf

[10] J. Burke. (2007, August). "Hard to Find Information About Distribution Systems." [Online]. Available URL: http://quanta-technology.com/sites/default/files/doc-files/Burke-Hard-toFind-Vol-2.pdf

[11] ElectriCities. (2013, September 12). Sizing of Transformers. [Online]. Available URL: http://www.electricities.com/Libraries/Training/Transformer_Sizing_Presentation.sflb.ashx

[12] IEEE Guide for Loading Mineral-Oil-Immersed Transformers, IEEE C57.91-1995

[13] J. Parmar. "Demand Factor-Diversity Factor-Utilization Factor-Load Factor." [Online]. Available URL: http://electricalnotes.wordpress.com/2011/10/31/demand-factor-diversityfactor-utilization-factor-load-factor/, Oct. 312011 [12/9/2013]. 
[14] International Electrotechnical Commission. (2013, December 9). Load Curve. [Online]. Available URL: http://www.iec.ch/etech/2012/etech_0712/pic_tech/tech-

3_load_curve.jpg

[15] (2013, October 31). List of production battery electric vehicles. [Online]. Available URL: http://en.wikipedia.org/wiki/List_of_production_battery_electric_vehicles

[16] Drive Electric Ohio. (2012, July). Charger Info. [Online]. Available URL: http://www.driveelectricohio.org/wp-content/uploads/2012/07/ChargerInfographic.jpg

[17] S. Rahman, et.al. "Challenges of PHEV Penetration to the Residential Distribution Network." IEEE Power \& Energy Society General Meeting, 2009, pp. 1-8.

[18] Power Engineering Research Center. Transformer Overloading and Assessment of Loss-ofLife for Liquid-Filled Transformers [Online]. Available URL:

http://www.pserc.wisc.edu/documents/publications/reports/2011_reports/Sen_T 25_Final_Report_Feb_2011.pdf

[19] E. A. Thomas et al. (2013, August 2). "Remotely Accessible Instrumented Monitoring of Global Development Programs: Technology Development and Validation." [Online]. Available URL: http://www.mdpi.com/2071-1050/5/8/3288

[20] E. A. Thomas et al. (2011, September 9). Technology Description. [Online]. Available URL: http://www.pdx.edu/sweetlab/technology

[21] TLX Group Inc. (2012). Ultra Low Voltage Bootstrap Converter. [Online]. Available URL: http://www.customthermoelectric.com/powergen/pdf/ELC-W0422-X_R2_spec_sht.pdf

[22] KEPKO KDN. (2013). Digital Transformer with Built-in sensors. [Online]. Available URL: https://www.kdn.com/home3/we/gs/WEGS_0405.jsp 


\section{Appendix A Vehicle Data}

\begin{tabular}{|c|l|c|}
\hline Year of introduction & \multicolumn{1}{|c|}{ Car } & $\begin{array}{c}\text { Battery } \\
\text { Capacity [kWh] }\end{array}$ \\
\hline 1996 & Chevy EV1 & 18.7 \\
\hline 1999 & Chevy EV1 & 26.4 \\
\hline 2009 & Mitsubishi i-MiEV & 16 \\
\hline 2010 & Leaf & 24 \\
\hline 2011 & Ford Focus & 23 \\
\hline 2009 & Tesla 60Wh & 60 \\
\hline 2009 & Tesla 85kWh & 85 \\
\hline 2010 & Chevy Spark & 21.3 \\
\hline 2012 & Prius Plug in & 4.4 \\
\hline 2011 & Volt & 16.5 \\
\hline 2011 & Smart EV & 17.6 \\
\hline 2013 & Toyota RAV4 EV & 41.6 \\
\hline
\end{tabular}




\section{Appendix B Testing Procedures}

\section{Caution}

When a test is in progress this surface will heat to $100{ }^{\circ} \mathrm{C}$.

Do not touch.

Verify surface temperature by attaching thermocouple with aluminum tape or with an IR thermometer.

\section{Operation}

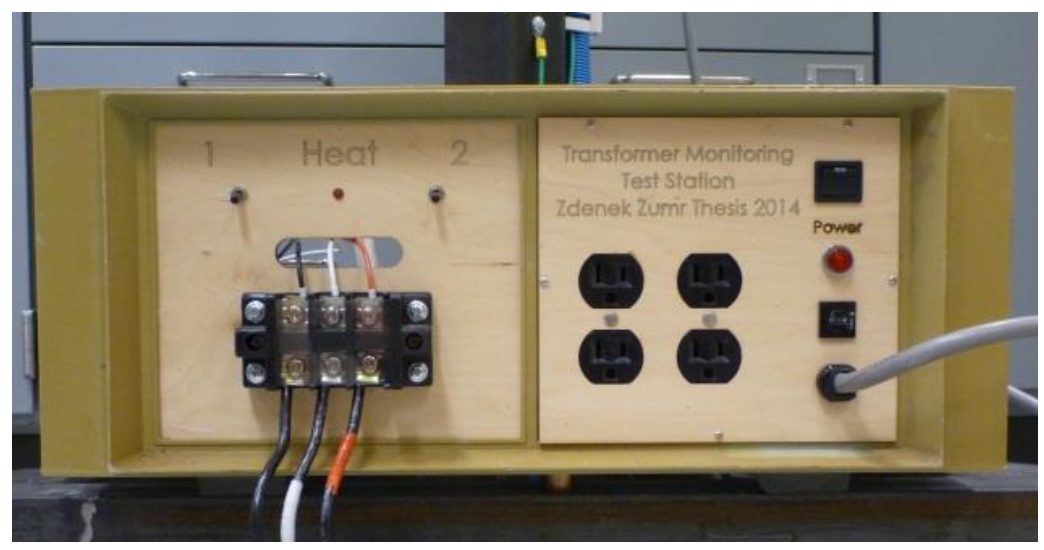

Fig. 30: Faceplate Transformer Monitoring Test Station

To turn on flip Power switch, the red power light will come on and turn on power to the step down transformer and the utility outlets on the front panel.

A 15 A resettable fuse protects the unit from overloads.

To turn on the heating elements flip switches Heat 1 or 2 or both, Fig 30. The red Heat indicator LED will light up to show heating is in progress. 


\section{Appendix C Monitor Sample Data Excerpt}

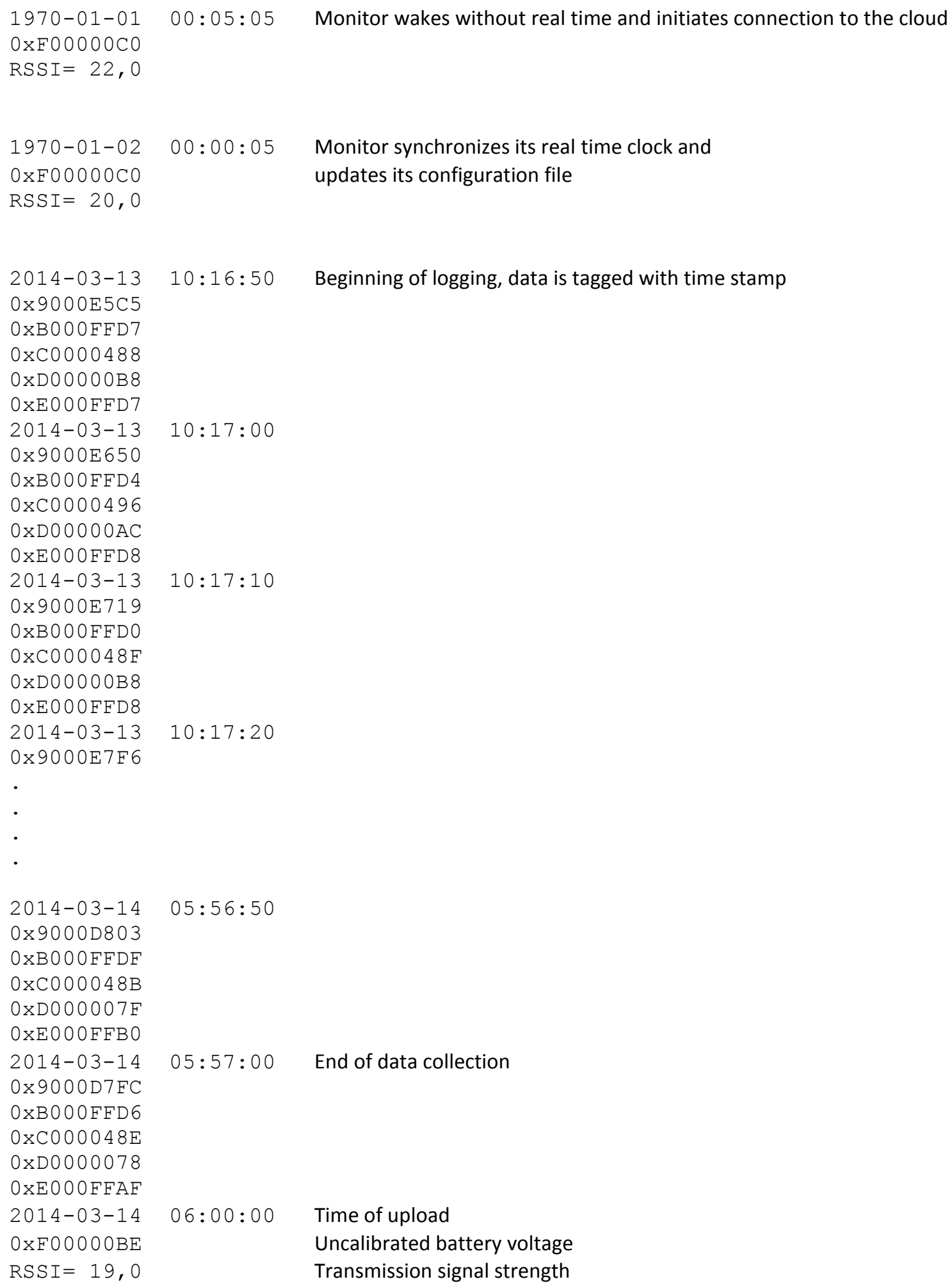

Beginning of logging, data is tagged with time stamp 